\title{
Physically Based Finite Element Modeling Method to Predict Metallic Bonding in Cold Spray
}

\author{
Saeed Rahmati ${ }^{1} \cdot$ Bertrand Jodoin $^{1}$
}

Submitted: 6 October 2019/in revised form: 10 February 2020/Published online: 21 February 2020

(C) ASM International 2020

\begin{abstract}
The cold spray (CS) process is unique due to its high strain rate deformation and particle deposition in solid state. In situ investigation of this process is challenging. Therefore, numerical methods have been used to simulate this process and provide a better ground for furthering the understanding of the process physics. Metallurgical bonding occurs during the deformation process at the particle/substrate interface during coating build-up. Up to now, several studies have been performed to predict the material behavior during this process. Although several studies have been done to predict the bonding in CS, none of them was able to show the occurrence of localized metallurgical bonding. In this study, a novel modeling method is
\end{abstract}

proposed to predict the occurrence and strength of localized metallurgical bonds in the CS process through finite element method. The process physics and implementation method are explained in details. Critical velocities of aluminum, copper, and nickel were predicted and compared with experimental data to validate the method. In addition, the proposed method is able to show the localized metallurgical bonding at the interface between particle and substrate. Comparison between the predicted bonding area with the proposed method and experimental data from the literature showed good agreement.
Saeed Rahmati

sr_987@yahoo.com; saeed.rahmati@uottawa.ca

1 Cold Spray Research Laboratory, University of Ottawa, Ottawa, ON, Canada 


\section{Graphic Abstract}
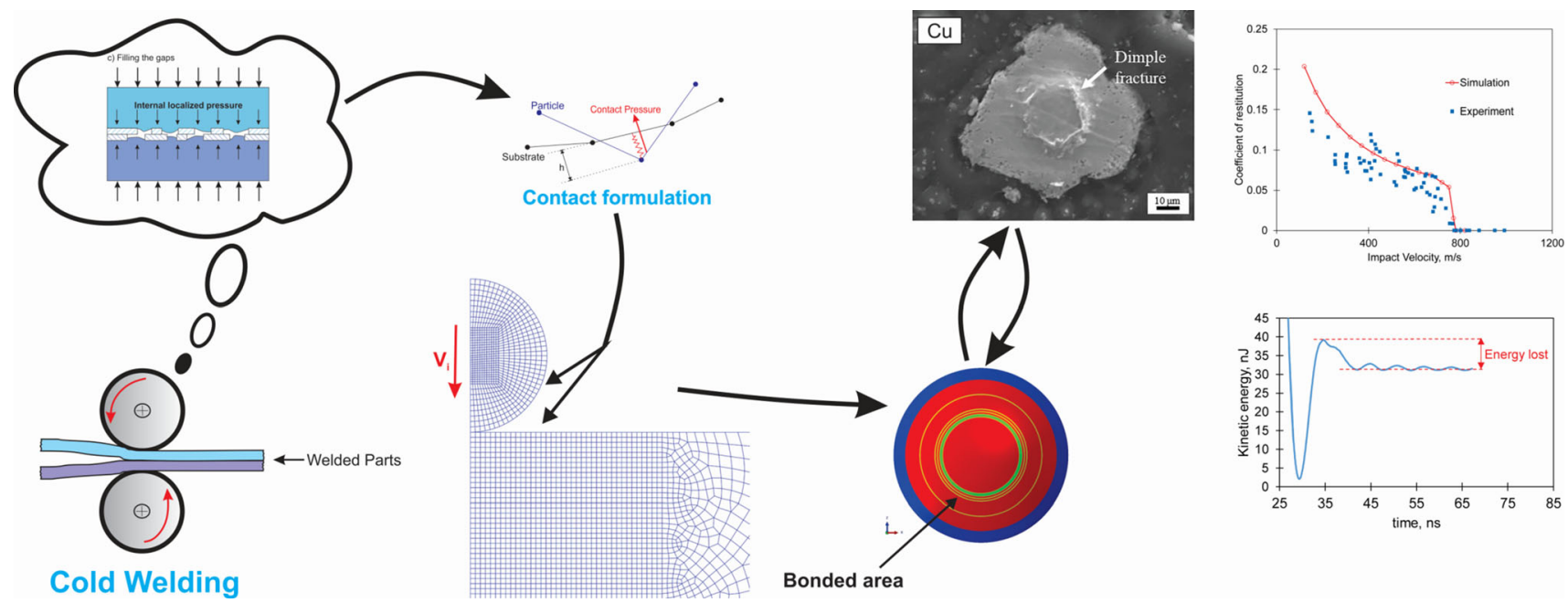

Keywords cold spray $\cdot$ critical velocity $\cdot$ metallurgical bonding $\cdot$ simulation

\section{Introduction}

Cold gas dynamic spraying or simply cold spray (CS) is a deposition method in which the particles are accelerated in a de Laval nozzle using a relatively low-temperature supersonic gas flow maintaining them below melting point prior to impacting and plastically deforming on the substrate (Ref 1). Although CS was developed first as a coating method (Ref 2), it is also used nowadays as an additive manufacturing process (Ref 2). CS offers potential in diverse applications due to its ability to spray a wide variety of materials. For instance, spraying metals on metals has been achieved from soft tin (Ref 3,4$)$ to hard MCrAlYs (Ref 5, 6). Metallizing polymers or deposition of polymers onto metals has also been achieved (Ref 7, 8), and even spraying metals on ceramics has been demonstrated (Ref 9,10). This special ability of CS makes it a unique process and thus the development of a thorough understanding of the process fundamentals has been the topic of numerous works over the last decade and is still underway (Ref 1, 11-18).

The large kinetic energy of the sprayed particles prior to their impact onto the substrate leads to severely deformed particles occurring at high strain rates, i.e., up to $10^{9} \mathrm{~s}^{-1}$ (Ref 19-21). Understanding the particle deformation/deposition behavior and the bonding mechanisms involved in CS has been the primary focus of scientific works for decades (Ref 1, 18, 19, 22-28). Mechanical anchoring and metallurgical bonding have been established as the two main bonding mechanisms involved in CS. Mechanical anchoring is a non-chemical phenomenon occurring when

particles are physically trapped in the substrate intricate surface topology and interlock with it (Ref 29, 30). By contrast, metallurgical bonding involves chemical bonds that are usually stronger than mechanical bonds. It requires oxide-free surfaces to allow intimate metal-to-metal contact and appropriate localized pressure to allow the chemical bond to be established (Ref 2). The necessity of removing the native oxide layer on particle-substrate surfaces for the creation of metallurgical bonding is widely acknowledged in the CS literature but the details of the in situ oxide layer removal process is still a point of contention. Numerous studies have indicated that adiabatic shear instability is the main mechanism responsible for the oxide layer breakup and cleaning away (removal) (Ref $18,19,22,23,31-34)$, while some have elaborated that metallurgical bonding in CS is not related to the occurrence of adiabatic shear instability (Ref 24, 35). In addition, partial melting in the contact region has also been deemed responsible for the localized oxide layer removal and chemical bonding upon solidification (Ref 36, 37). Despite these slight differences in the actual oxide removal process, all studies agree that the impacting particle requires a minimum velocity to adhere to the substrate, the critical velocity.

The critical velocity could be an indication of the onset of metallurgical bonding in CS, although adhesion solely attributed to mechanical anchoring also requires a critical velocity to be reached ( $\operatorname{Ref} 2,38-40)$. The critical velocity is dependent on the particle and substrate material properties, particle size, substrate and particle impact temperatures, and oxide or hydroxide layer thickness on both particle and substrate (Ref 19, 38, 41, 42). Since the deformation process in CS happens over only a few nanoseconds, in situ investigation on particle deformation and bonding mechanisms is a challenging task. Hassani- 
Gangaraj et al. (Ref 43) have recently used an in situ observation technique derived from Lee et al. and Veysset et al. (Ref 44,45$)$ and adapted to CS to assess precisely the critical velocity of different materials and particle sizes upon impact with a polished surface finish substrate. Prior to that several numerical studies have been performed to evaluate the critical velocity and/or simulate particle bonding in CS (Ref 18, 22, 23, 25, 46-52). For instance, Assadi et al. (Ref 1) have shown that the critical velocity can possibly be linked with the occurrence of adiabatic shear instability during the impact and suggested a semiempirical equation to calculate the critical velocity. Similarly, Meng et al. (Ref 53) proposed a model based on $\mathrm{PEEQ}^{2}$, which is defined as the average equivalent plastic strain over all particle elements to calculate the critical velocity. They suggested that the critical velocity can be determined numerically when the slope of $\mathrm{PEEQ}^{2}$ is changed significantly by increasing the initial velocity. To simulate bonding, Yildirim et al. (Ref 54) used the surfacebased cohesive behavior option available in the commercially available finite element method (FEM) software ABAQUS/Explicit. In addition, Profizi et al. (Ref 55) and Manap et al. (Ref 56) also used two different cohesive zone models and have simulated the bonding in CS using the smooth particle hydrodynamics (SPH) method. Surfacebased cohesive behavior is a simple way to model cohesive connections with negligibly small interface thicknesses using the traction-separation constitutive model. This method allows simulating cohesive interactions such as two "sticky" surfaces (surfaces can bond after coming into contact) (Ref 57). Although informative, a limitation of cohesive models lies with the fact that it is impossible to model the exact bonding behavior because the surfacebased cohesive option acts exactly like a glue; hence, the particles stick to the substrate upon the initial contact. As such, this model does not include the requirement of breaking the native oxide layer and providing fresh surfaces for creating metallurgical bonding. In addition, the overall bond strength in this method relies on the glue strength [effective cohesive strength in FEM modeling (Ref 57)] which must be obtained by trial and error. Kurochkin (Ref 58) has developed a model to evaluate the relative bond strength between the particle and substrate based on the activation energy of the chemical bonds and the recoil coefficient. Wu et al. (Ref 59) further developed this idea and have shown the relationship between the particle velocities and the bond strength between particle and substrate. In this fundamental model, particle deposition can occur when the adhesion energy is higher than the rebound energy, providing important information about the adhesion process. However, there is a lack of information about the oxide layer removal process and inclusion in this model, and the adhesion energy is set as a function of sublimation energy, which is potentially different from the fractured energy required to debond the atoms in solid phase. Xie et al. (Ref 60) calibrated an empirical model based on the experimental data and simulate the collisions of aluminum particles to an aluminum/sapphire substrate. Therefore, they could predict the extreme material behavior in high strain rate collisions.

The main objective of this study is to present the first steps of a new model that allows predicting localized metallic bonding in CS. The proposed model is taking into account the physics of oxide layer breakage. The model was used to investigate the bonding conditions of the local contact surfaces upon impact. The use of this model allows tracking closely the contact area during the deposition process. It divides the contact elements into three different groups: (a) elements which never met the required conditions for bonding during the impact process; (b) elements which met the bonding conditions at some point during the impact but fractured during the rebounding; and (c) elements which are bonded to the substrate at the end of the impact process. In addition, the critical velocity of aluminum, copper, and nickel powders with different diameters was predicted using the model and compared with experimental results available in the CS scientific literature for validation (Ref 43, 61).

\section{Deformation Process During CS Impact}

The deformation process during CS impact is presented in this section using FEM theory to describe the known process physics that helped develop the model proposed in this work

As mentioned before, particles require a minimum velocity, i.e., critical velocity, to adhere to the substrate. Particles with lower velocity than the critical velocity hit the substrate, deform plastically, and bounce off from the substrate. SEM images of deposited particles show severe plastic deformation, as shown in Fig. 1 (Ref 1). This large

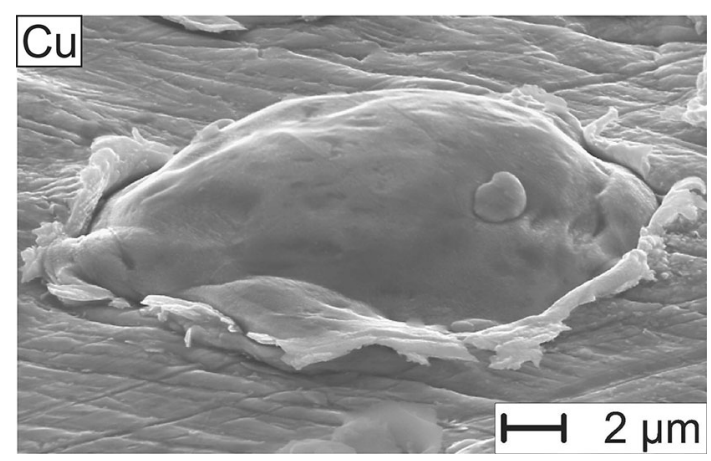

Fig. 1 SEM image of a copper particle impacted on a copper substrate (Ref 1) 
plastic deformation is attributed to the large kinetic energy of the particle prior to impact.

At time zero, just before the impact with the substrate, the total system energy (one single particle and the substrate) is equal to the particle kinetic energy and particle and substrate internal energy. Based on energy balance, the system total energy must be constant. In FEM models, the total energy is typically defined as follows:

$E_{\mathrm{Total}}=E_{\mathrm{I}}+E_{\mathrm{V}}+E_{\mathrm{FD}}+E_{\mathrm{KE}}-E_{\mathrm{W}}$

where $E_{\mathrm{I}}$ is the internal energy of the system, $E_{\mathrm{V}}$ is the viscous energy dissipated by damping mechanisms including bulk viscosity damping and material damping in the system, $E_{\mathrm{FD}}$ is the energy dissipated by friction, $E_{\mathrm{KE}}$ is the kinetic energy of the system, and $E_{\mathrm{W}}$ is the work done by externally applied load to the system. The sum of these energies should be constant, while in numerical models, it is approximately constant with an error of less than one percent (Ref 57). In the CS process, the external work is zero, and $E_{\mathrm{V}}$ and $E_{\mathrm{FD}}$ are negligible compare to the internal and kinetic energies. Therefore, the total energy can be assumed as the sum of internal and kinetic energy.

In FEM methods, the internal energy is described as follows:

$E_{\mathrm{I}}=E_{\mathrm{E}}+E_{\mathrm{P}}+E_{\mathrm{CD}}+E_{\mathrm{A}}$

where $E_{\mathrm{E}}$ is the recoverable elastic strain energy, $E_{\mathrm{P}}$ is the energy dissipated through the inelastic processes such as plasticity, $E_{\mathrm{CD}}$ is the dissipated energy through the viscoelasticity or creep that is zero in CS process, and $E_{\mathrm{A}}$ is the artificial energy which is primarily the energy dissipated to control hourglassing deformation that is used to avoid having nonphysical deformation for reduced integration elements in numerical methods (Ref 57). As long as the artificial energy is small compared to other internal energies, the results are reliable (Ref 57). In summary, the total system energy in CS can be shortened as follows:

$E_{\text {Total }}=E_{\mathrm{E}}+E_{\mathrm{P}}+E_{\mathrm{KE}}$

Figure 2 shows a typical time history (Ref 62) of total system energy, particle kinetic energy, and the total dissipated energy through the plastic deformation process in CS. According to the literature, about 90 percent of the dissipated energy through plastic deformation goes to heat (Ref 63, 64). This figure indicates that most of the kinetic energy is dissipated through plastic deformation. Although the recoverable elastic strain energy is small compared to the dissipated plastic energy, the particle can bounce off from the substrate due to this stored elastic energy.

Distribution of elastic strain energy during the process is mapped in Fig. 3. Following the particle impact, deformation happens in both particle and substrate, which causes elastic energy storage in both materials. In addition, as soon as the particle hits the substrate, deceleration of the particle and acceleration of the substrate occur. It can be seen that the amount of elastic energy stored in the substrate is much larger than the elastic energy stored in the particle and that the particle bounces off from the substrate at the end of simulation. Both particle and substrate start to rebound together, while they are still in contact. The substrate then stops due to the boundary conditions and the particle detaches from the substrate. This rebounding is due to the releasing of elastic energy in the material. Conventional contact methods in FEM do not consider the bonding between two elements. Therefore, particles always bounce off from the substrate in FEM simulations. As stated previously, several studies have modeled the metallic bonding by using the cohesive element type, or surface-based cohesive contact method existing in FEM library (Ref $39,55,56,65,66)$. These methods were not developed to study and predict metallic bonding. The proposed method is employed instead of those methods to study and predict the metallic bonding in CS, with consideration of the oxide layer on both particle and substrate surfaces.

\section{Modeling Method}

The behavior of a single CS particle impacting on a substrate is studied using the commercially available FEM software ABAQUS/Explicit that has been used profusely in CS studies (Ref 67-71). An axisymmetric geometry is used by assuming the impact of a perfectly spherical particle on a flat substrate. The substrate geometry is modeled as a cylinder with a radius and height five times larger than the particle radius (Ref 21). It has been shown that simulating the large plastic deformation found in CS causes severe element distortion when using Lagrangian elements (Ref 33). To reduce the resulting computational errors, the Arbitrary Lagrangian-Eulerian (ALE) method (Ref 57) is used to remesh the model 5 times in each increment. According to the literature (Ref $1,21,34,72)$, convergence of the final particle shape is obtained when the mesh size is set to $1 / 50$ of the particle diameter. However, in this work, convergence for predicting critical velocity was checked by choosing different mesh sizes and the results showed that the mesh size should set to be 1/200 of particle diameter, as detailed in the "Results and Discussion" section. The particle and substrate material elastic behavior was modeled by a linear Mie-Gruneisen equation of state (EOS) which is adequate for impacts at high velocities (Ref $21,73)$. In this study, three different materials were used to model particle-substrate, i.e., aluminum on aluminum, copper on copper, and nickel on nickel. The materials properties are given in Table 1. The initial temperature of 
Fig. 2 History of particle kinetic energy, plastic dissipation energy for whole system, and total energy of system, for a 30 -um aluminum particle impacting an aluminum substrate at $770 \mathrm{~m} / \mathrm{s}$
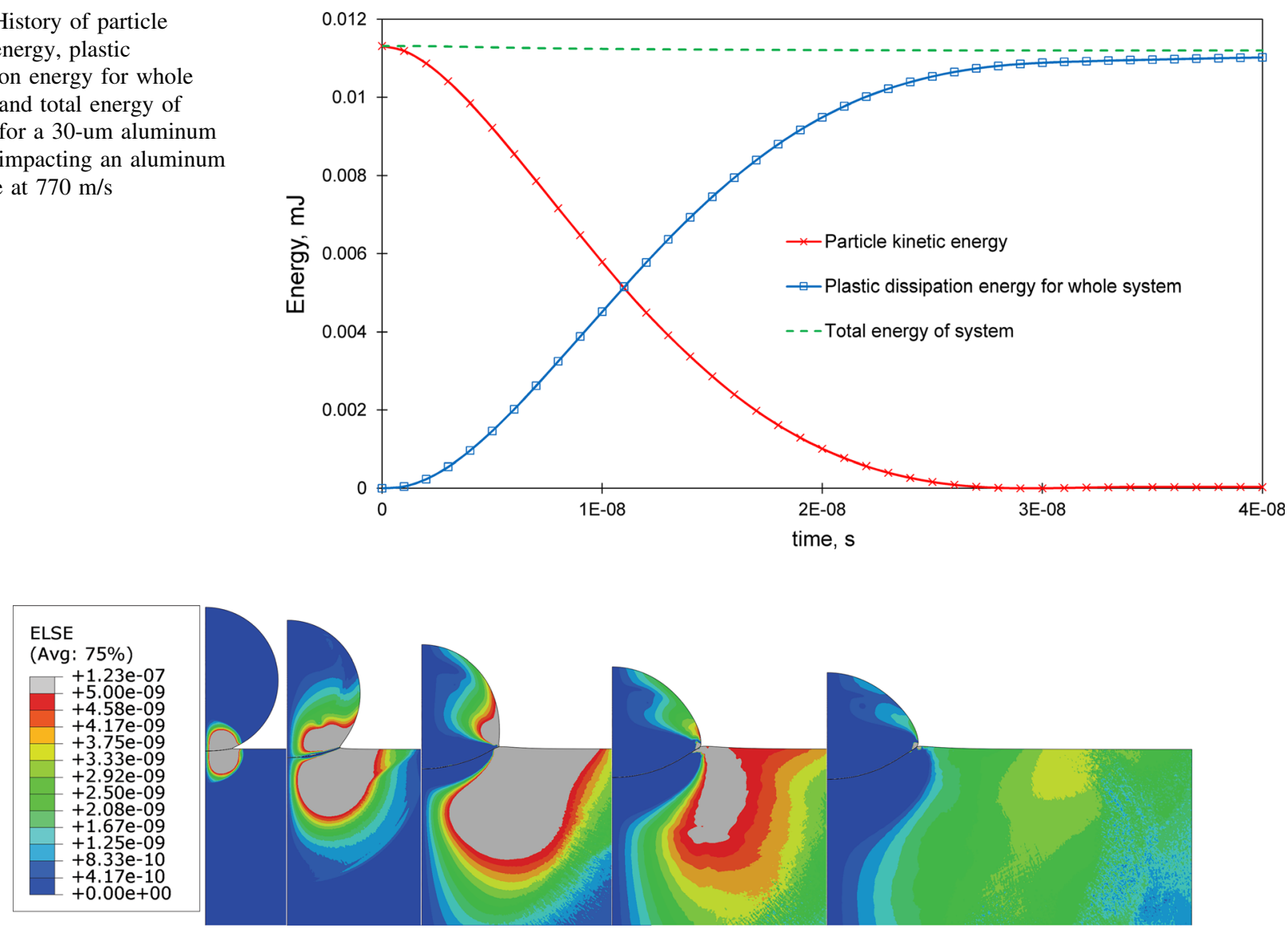

Fig. 3 Elastic energy distribution in 30-um aluminum particle and substrate during the whole deformation process, for initial impact velocity of $770 \mathrm{~m} / \mathrm{s}$

Table 1 Material properties (Ref 21, 72, 101)

\begin{tabular}{lccc}
\hline Properties & Aluminum (Ref 72) & Copper (Ref 21) & Nickel (Ref 101) \\
\hline Density $\left(\rho_{0}\right), \mathrm{kg} / \mathrm{m}^{3}$ & 2700 & 8960 & 8890 \\
Specific heat $\left(C_{\mathrm{p}}\right), \mathrm{J} / \mathrm{kg} \mathrm{K}$ & 910 & 383 & 456 \\
Thermal conductivity $(\kappa), \mathrm{W} / \mathrm{mk}$ & 237 & 386 & 91 \\
Melting temperature $\left(T_{\mathrm{m}}\right), \mathrm{K}$ & 934 & 1356 & 1728 \\
Shear modulus $(G), \mathrm{GPa}$ & 26 & 45 & 76 \\
Grüneisen's constant $\left(\Gamma_{0}\right)$ & 2.14 & 1.99 & 1.93 \\
Speed of sound $\left(c_{0}\right), \mathrm{m} / \mathrm{s}$ & 5292 & 3933 & 4650 \\
Hugoniot slope $(s)$ & 1.4 & 1.5 & 1.45 \\
\hline
\end{tabular}

both the particle and substrate was assumed to be $300 \mathrm{~K}$ for all cases studied.

\section{Material Model}

The Preston-Tonks-Wallace (PTW) material model (Ref 74) which is one of the best models for predicting material behavior at high strain rates (Ref $21,75,76)$ was used to model the impact process. This model is expressed as follows (Ref 21):

$$
\begin{aligned}
& \sigma=2\left[\tau_{\mathrm{s}}+\alpha \ln \left[1-\varphi \exp \left(-\beta-\frac{\theta \varepsilon_{\mathrm{p}}}{\alpha \varphi}\right)\right]\right] \mu(p, T) \\
& \alpha=\frac{s_{0}-\tau_{\mathrm{y}}}{d} \beta=\frac{\tau_{\mathrm{s}}-\tau_{\mathrm{y}}}{\alpha} \varphi=\exp (\beta)-1
\end{aligned}
$$

where $\varepsilon_{\mathrm{p}}$ is the plastic strain, $\tau_{\mathrm{s}}$ the normalized work hardening saturation stress, $\tau_{\mathrm{y}}$ the normalized yield stress, $\theta$ the hardening constant, $\mathrm{d}$ a dimensionless material constant and $s_{0}$ the value of $\tau_{\mathrm{s}}$ at zero temperature. Moreover, $\mu$ denotes the shear modulus and is assumed to be a function of temperature and density of the material. 
According to Banerjee (Ref 76), the MTS shear modulus model which is only function of the temperature is able to predict the shear modulus accurately. Therefore, this simple model is preferred to use instead of other complex models, given as:

$\mu(T)=\mu_{0}-\frac{D}{\exp \left(T_{0} / T\right)-1}$

where $\mu_{0}$ is the shear modulus at $0 \mathrm{~K}, D, T_{0}$ are material constants, and $T$ is the material temperature. $\tau_{\mathrm{s}}$ and $\tau_{\mathrm{y}}$ are defined as:

$$
\begin{gathered}
\tau_{\mathrm{s}}=\max \left\{s_{0}-\left(s_{0}-s_{\infty}\right) \operatorname{erf}\left[k \hat{T} \ln \left(\frac{\gamma \dot{\xi}}{\dot{\varepsilon}_{p}}\right)\right], s_{0}\left(\frac{\dot{\varepsilon}_{p}}{\gamma \dot{\xi}}\right)^{s_{1}}\right\} \\
\tau_{\mathrm{y}}=\max \left\{y_{0}-\left(y_{0}-y_{\infty}\right) \operatorname{erf}\left[k \hat{T} \ln \left(\frac{\gamma \dot{\xi}}{\dot{\varepsilon}_{p}}\right)\right],\right. \\
\left.\min \left\{y 1\left(\frac{\dot{\varepsilon}_{\mathrm{p}}}{\gamma \dot{\xi}}\right)^{y_{2}}, s_{0}\left(\frac{\dot{\varepsilon}_{\mathrm{p}}}{\gamma \dot{\xi}}\right)^{s_{1}}\right\}\right\}
\end{gathered}
$$

where $\hat{T}=T / T_{\mathrm{m}}, \mathrm{T}$ is the temperature, $T_{\mathrm{m}}$ the melting temperature, $s_{\infty}$ the value of $\tau_{\mathrm{s}}$ near the melting temperature, $y_{0}$ and $y_{\infty}$ the values of $\tau_{\mathrm{y}}$ at zero and at very high temperature, respectively. Furthermore, $\gamma, k, s_{1}, y_{1}$ and $y_{2}$ are all material parameters and

$\dot{\xi}=\frac{1}{2}\left(\frac{4 \pi \rho}{3 M}\right)^{1 / 3}\left(\frac{\mu(\rho, T)}{\rho}\right)^{1 / 2}$

where $\rho$ is the density and $M$ denotes the atomic mass. The PTW material model is not included in the ABAQUS library. In the previous study (Ref 21), this model was implemented into ABAQUS/Explicit via VUHARD user subroutine.
The yield strength of pure aluminum and 1100-0 aluminum as a function of strain rate were reported by Casem et al. (Ref 77). This result is shown in Fig. 4 to compare with the predicted result by PTW model using material model parameters reported by Price et al. (Ref 78). This comparison shows that this set of parameters is not able to follow the experimental yield strength in a wide range of strain rates. Therefore, the least square method which is a standard method in regression analysis to find the best fit for a set of data was used to modify the reported parameters by Price et al. to better fit Casem et al. experimental data. The predicted results using these new parameters are also plotted in Fig. 4 and show that these parameters are more suitable for modeling.

The PTW material model parameters for aluminum, copper, and nickel are shown in Tables 2, respectively.

\section{Metallic Bonding in CS}

In CS, it is hypothesized that when a particle impacts the substrate at sufficient speed, leading to localized high strain rates, the oxide layers on both the particle and substrate surfaces break up due to the extensive localized material deformation (Ref 2, 13, 79). This creates new freshly exposed metallic surfaces. The intimate contact between those fresh oxide-free layers causes metallic bonding (Ref 80). This bonding mechanism is assumed to be similar to the one experienced in the cold welding $(\mathrm{CW})$ process (Ref $81-90)$. Figure 5 illustrates the bonding model proposed by Bay et al. (Ref 81,82$)$ for the $\mathrm{CW}$ process of two metallic plates pressed together to achieve cold welding.

In the initial state, Fig. 5(a), there is an oxide layer on each of the two mating surfaces being put in contact. Under the loading forces applied, the pressure developing at the
Fig. 4 Comparison of predicted stress by PTW model using fitted parameters and parameters proposed by Price et al. (Ref 78) with experimental results (Ref 77)

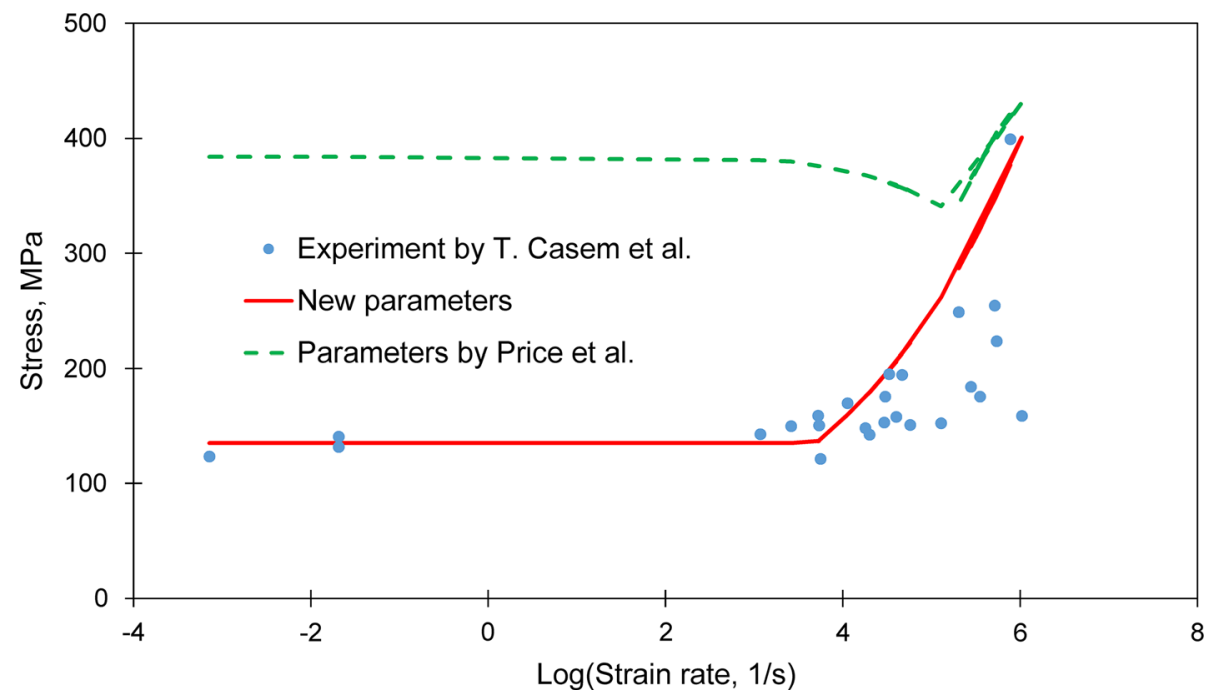


Table 2 PTW material model parameters for aluminum, copper (Ref 21), and nickel (Ref 101)

\begin{tabular}{llll}
\hline PTW parameters & \multicolumn{1}{c}{ Aluminum } & Copper (Ref 21) & Nickel (Ref 101) \\
\hline Strain rate dependence constant $(\gamma)$ & $2.04 \mathrm{e}-5$ & $1 \mathrm{e}-5$ & $1 \mathrm{e}-5$ \\
Strain hardening rate $(\theta)$ & 0.01156 & 0.025 & 0.01 \\
Strain hardening constant $(d)$ & 3 & 2 & 2 \\
Yield stress constant at $0 \mathrm{~K}\left(y_{0}\right)$ & 0.0115 & 0.0001 & 0.0001 \\
Yield stress constant at melting $\left(y_{\infty}\right)$ & 0.002003 & 0.0001 & 0.0001 \\
Medium strain rate constant $\left(y_{1}\right)$ & 0.0168 & 0.094 & 0.094 \\
Medium strain rate constant $\left(y_{2}\right)$ & 0.2339 & 0.575 & 0.575 \\
High strain rate exponent $\left(s_{1}\right)$ & 0.2034 & 0.25 & 0.25 \\
Saturation stress at $0 \mathrm{~K}\left(s_{0}\right)$ & 0.01489 & 0.0085 & 0.0045 \\
Saturation stress at melting $\left(s_{\infty}\right)$ & 0.002819 & 0.00055 & 0.00055 \\
Temperature dependence constant $(\kappa)$ & 1.3 & 0.11 & 0.11 \\
Atomic mass $(M), \mathrm{kg}$ & $4.48039 \times 10^{-23}$ & $1.05521 \times 10^{-25}$ & $9.74627 \times 10^{-26}$ \\
Shear modulus at $0 \mathrm{~K}\left(G_{0}\right), \mathrm{GPa}$ & 28.8 & 50 & 85.1 \\
Material constant $(\mathrm{D}), \mathrm{GPa}$ & 3.44 & 3 & 9.13 \\
Temperature material constant $\left(T_{0}\right), \mathrm{K}$ & 215 & 165 & 269 \\
\hline
\end{tabular}

interface induces plastic deformation in the metallic plates. These deformations eventually become large enough, and the native oxide layers break up in parts due to their lower ductility, and move with the metallic parts they remain attached to, as shown in Fig. 5(b). Following this creation of gaps and under the high localized pressure existing at the interface, the freshly exposed metal is extruded into the gaps, as illustrated in Fig. 5(c). Upon contact with the other clean metal part and under the high localized pressure, a metallic bonding is created, as shown in Fig. 5(d).

Conrad and Rice (Ref 80) experimentally investigated the adhesion of clean fresh surfaces of different FCC metals. Using metallic specimens previously fractured in an ultrahigh vacuum (to avoid oxidation effects), they observed that the bond strength $\left(\sigma_{\mathrm{B}}\right)$ obtained between these perfectly clean surfaces put into contact under a pressure $P$ (in the same ultrahigh vacuum environment) is approximately equal to this applied pressure, that is:

$\sigma_{\mathrm{B}} \cong P$

where $P$ is the normal pressure applied to the surfaces.

However, metallic materials are usually used in oxygen containing environment. As such, they generally have a native protective oxide layer and possibly a contaminant film on their surfaces resulting from manufacturing processes or simply handling operations. Therefore, Bay et al. (Ref 81) introduced a surface expansion factor, $\Psi$, which shows the ratio of available fresh oxide-free surfaces for bonding to initial surface area:

$\Psi=\frac{A_{1}-A_{0}}{A_{1}}$

where $A_{0}$ and $A_{1}$ are the initial and the final surface area, respectively (Ref see Fig. 5(e) and (f)]. It was established experimentally that bonding is not obtained until a threshold has been achieved for the surface expansion, $\Psi_{\text {min }}$, as shown in Fig. 6 (Ref 91) for copper-copper, aluminum-aluminum, and copper-nickel combinations.

Beyond this material-dependent threshold value, the bond strength increases quickly with $\Psi$. The bond strength eventually reaches the strength of the weaker of the two metals, with the required $\Psi$ for this occurrence also function of the material (Ref 91). The bond strength is thus a function of $\Psi$; hence, Eq (9) has been reformulated as follows (Ref 83):

$\sigma_{\mathrm{B}}=P \cdot \Psi$

The CW process is performed at low strain rates; hence, the strength of the materials is not changed significantly and remains below $250 \mathrm{MPa}$ for copper (Ref 91). However, according to McQueen and Marsh (Ref 92), the ultimate tensile strength of copper can exceed $15 \mathrm{GPa}$ under deformation occurring at high strain rate. Since the material deformation rate is high in the CS process, the material strength during CS can be much higher than during the $\mathrm{CW}$ process.

In Fig. 6, it is assumed that beyond $\Psi_{\min }$, surface expansion generates sufficient fresh metal areas available for bonding, and also that the contact pressure was enough to fill the created gaps by fresh metals. Moreover, Eq 11 allows determining the bond strength as a function of pressure. Therefore, in their original forms, both Fig. 6 and Eq 11 assume that the pressure is adequate for fresh metal to flow in the oxide gaps and merge.

However, a model refinement was implemented by determining the pressure which is required to allow material flowing through the gaps properly. It was found that this pressure is dependent on the surface expansion and the 


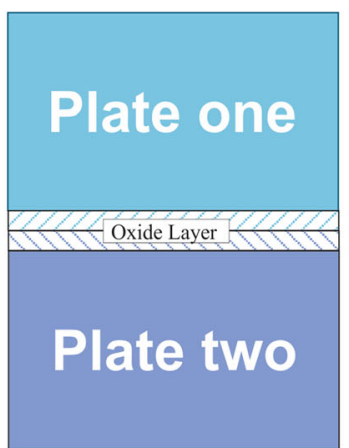

(a) Initial State

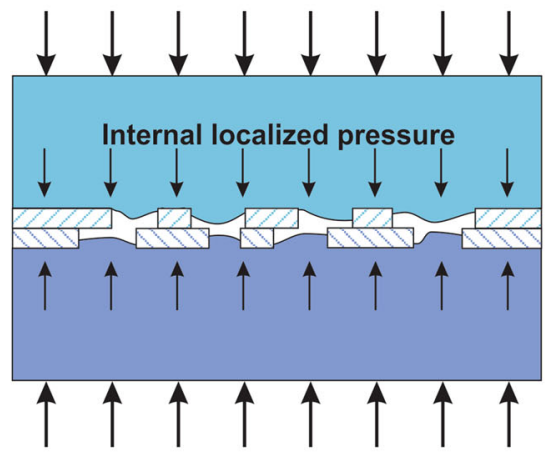

(c) Filling the gaps

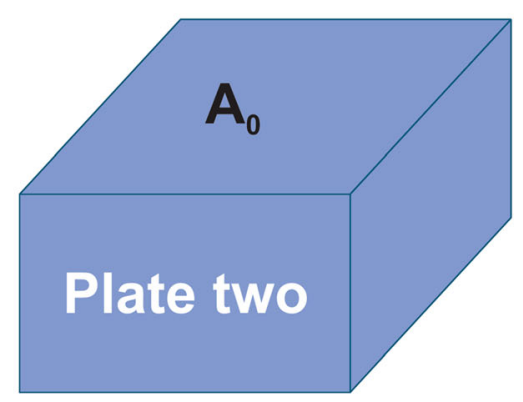

(e) initial state

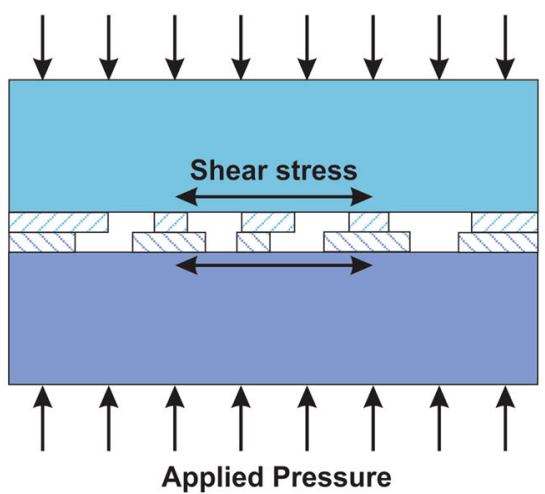

(b) Break-up oxide layer



(d) Creating metallic bonding

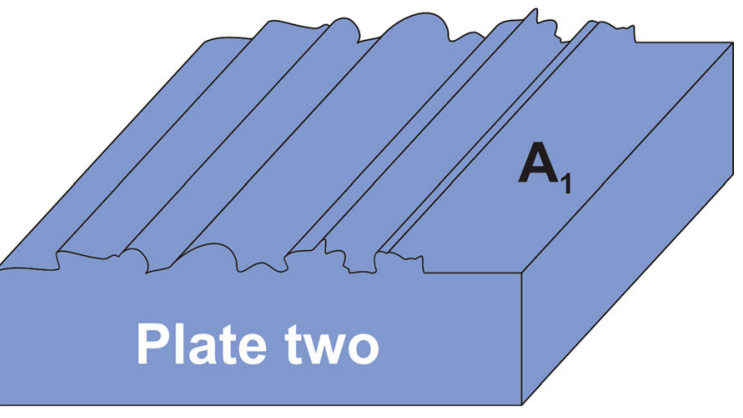

(f) final state

Fig. 5 Schematic of the bonding model in the CW process proposed by Bay et al. (Ref 81, 82)

material yield strength (Ref 81$)$. Due to the work hardening during both $\mathrm{CW}$, and CS by plastic expansion (or plastic deformation) of the surfaces, the material yield strength is increased. In addition, the yield strength is a function of the deformation rate. Thus, the required pressure must be obtained based on the instantaneous status of the material (referred to as current yield strength). Figure 7 (Ref 81) shows the relationship between the required extrusion pressure as a function of surface expansion, proposed by Bay (Ref 81) using Johnson's (Ref 93) and Hill's (Ref 94) slip line analysis of plane strain extrusion through square dies.
One can observe that the required (extrusion) pressure is decreased by increasing the surface expansion $\Psi$. It can be used for cases for which $\Psi$ is larger than $\Psi_{\min }$ found in Fig. 6 to assess if the local pressure is sufficient to allow material flow through the gaps for achieving good metallic contact for bonding.

Another important difference between the CS and CW processes is the time scale. $\mathrm{CW}$ is a quasi-static process, while CS is a dynamic process operating at much higher strain rates. As mentioned earlier, the bond strength is strain rate dependent. In CS, surface expansion, material extruding, and merging are all occurring at high strain 


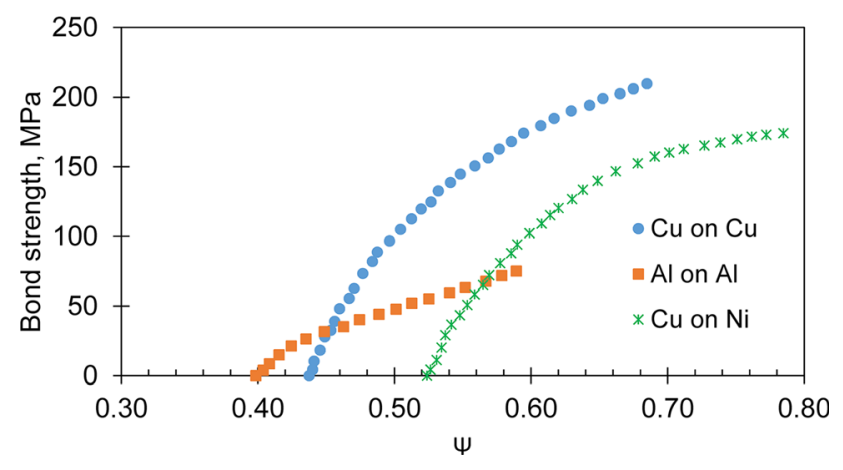

Fig. 6 Bond strength in rolling as a function of surface expansion, $\Psi$ (Ref 91). $\Psi_{\text {min }}$ for copper, aluminum, and nickel is $0.44,0.4$ and 0.52 respectively

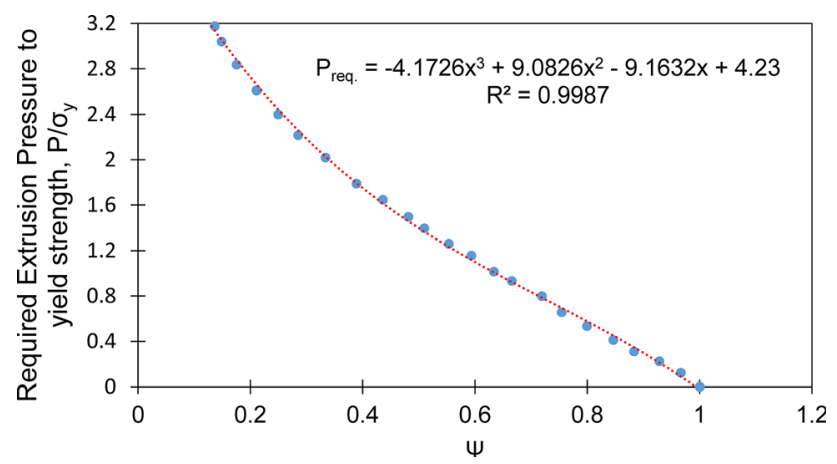

Fig. 7 Relationship between surface $(\Psi)$ expansion and the ratio of required extrusion pressure $(P)$ to instantaneous (current) yield strength $\left(\sigma_{\mathrm{y}}\right)(\operatorname{Ref} 81)$

rates. Since oxides are brittle materials, it is expected that the strain rate should not have a significant influence on their failure mechanism. Therefore, $\Psi$ is defined the same way in CS than CW. During plastic deformation, the applied stress on the surfaces is equal to the instantaneous yield strength of the surface materials. In the CS process, the applied stress is due to the local pressure, which is caused by the impact. Therefore, the normal stress $(P)$ on the surfaces is the pressure which induces the extrusion between the surfaces.

However, the bond strength (as defined by Eq 11) will be much higher than expected due to the high pressure $(P)$ required for extrusion at these high strain rates. During the rebounding process, the strain rate is much lower than during the impact process, thus the bond strength during rebounding should be less than the bond strength in the impact process. According to the von Mises yield criterion (Ref 95), yield strength of materials can be computed from the Cauchy stress tensor (Ref 57, 95). Thus, if the strain rate decreases, the yield strength declines as a consequence of the reduction in the normal stress (or applied pressure). In a simple hypothesis, it is assumed that both pressure and yield strength vary at the same rate; therefore, the bond strength during rebounding process would be changing at the same rate as the yield strength changes. Thus, Eq 11 can be rewritten as,

$\sigma_{\mathrm{B}}=P \cdot \Psi \cdot\left(\frac{\sigma_{\mathrm{y}-\mathrm{c}}}{\sigma_{\mathrm{y}-\mathrm{h}}}\right)$

where $\sigma_{\mathrm{y}-\mathrm{h}}$ is the yield strength at the moment of the bonding, and $\sigma_{\mathrm{y}-\mathrm{c}}$ is the current yield strength.

\section{Implementation of Metallic Bonding Model}

To implement the proposed bonding mechanism in FEM modeling, the simulation was divided into three steps. The steps are listed and then described: (1) simulating the first half of the impact; (2) post-processing to find the bonded elements; (3) restarting the rest of the simulation prior to rebounding.

As mentioned earlier, an axisymmetric geometry was chosen for this study. Figure 8(a) shows a simple axisymmetric element with 4 nodes, i.e., $A, B, C$, and $D$. In an axisymmetric geometry, the contact surface is modeled by only one edge, e.g., $A B$ ( $2 \mathrm{D}$ axisymmetric). The expansion in the contact surface can be defined by measuring the strain applied on the contact edge. Therefore, Eq 10 is rewritten as:

$\Psi=1-\frac{1}{e^{\varepsilon_{r}} e^{\varepsilon_{\theta}}}$

where $\varepsilon_{r} /$ is the logarithmic plastic strain along the element direction obtained by using transformation equations for plane strain (or radial strain), and $\varepsilon_{\theta}$ is the logarithmic hoop plastic strain. Furthermore, Fig. 8(b) shows a schematic of the elements in the particle-substrate contact region. Each element (denoted $E_{x}$ ) has two nodes (dots in the figure) in the contact surface, and each node is located between two nodes of a surface element belonging to the other solid surface. For instance, the "element one" $\left(E_{1}\right)$ which belongs to the particle has two nodes, i.e., $p_{1}$, and $p_{2}$. These nodes are, respectively, between the nodes $s_{1}-s_{2}$, and $s_{2}-s_{3}$, which belong to the substrate elements, i.e., $E_{3}$, and $E_{4}$.

\section{Simulating the First Half of the Impact}

In the CS process, bonding occurs in the contact region between particle and substrate surfaces. Therefore, the bonding mechanism has to be implemented via the contact subroutine applied for the simulation. The CS process can be divided into two parts. In the first part (or first half), the impact and plastic deformation occur at high strain rates. In the second part, the particle rebounds from the substrate due to the releasing of the elastic energy, at low strain rate. Thus, the bonding takes place in the first part but the 


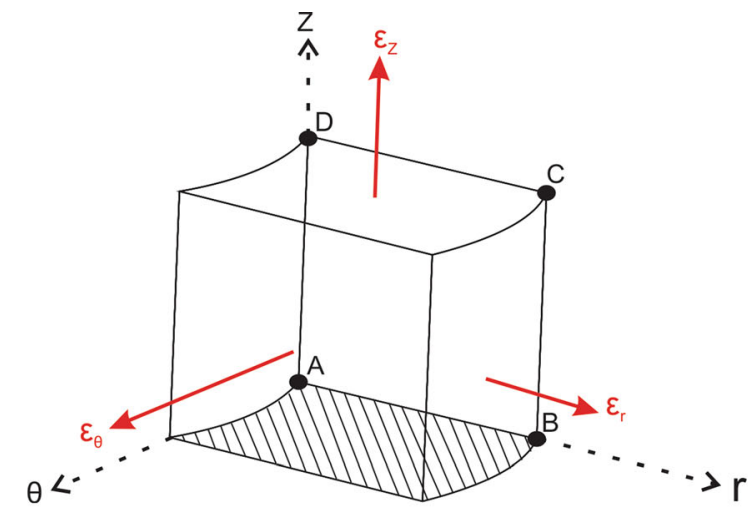

(a)

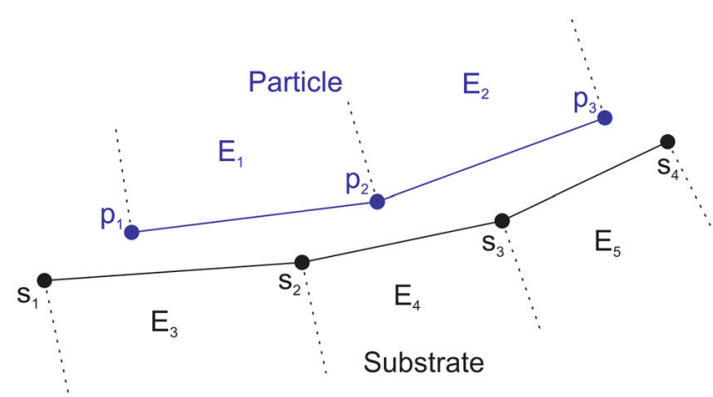

(b)

Fig. 8 (a) Schematic of an axisymmetric element (b) schematic of elements ( $E_{1}$ and $E_{2}$ are particle elements, $E_{3}, E_{4}$, and $E_{5}$ are substrate elements) in contact zone

bonding quality (comparison between the bond strength and "negative" pressure (or tension) described in "Metallic Bonding in CS" section) is checked during the second part.

It is a challenging task to know the exact time needed for each part (impact and rebounding) of the simulation in advance. The exact simulation time for the first part is the time that particle kinetic energy reaches to zero but it is inefficient to do a pre-simulation and find the exact required time for each cases. Therefore, the simulation time was estimated based on the first conducted simulation, and the output and restart files were set to be saved for 100 intervals (100 times during the simulation). Saving the restart files for 100 times allows to check the results and starts the second part when the kinetic energy of the particle is close to zero and prior to rebounding.

\section{Post-Processing to Find the Bonded Elements}

Following the first step (simulation of the first half of the impact, before the onset of elastic energy release), postprocessing was performed on the result file, i.e., $o d b$ file, by using a Python script. The algorithm flowchart is shown in Fig. 9. This script searches frame by frame both particle and substrate deformation to compute $\Psi$ and the applied pressure on each node of each element. For clarity, the algorithm flowchart shows the post-processing for element $E_{1}$ in Fig. 8(b).

As described in Fig. 8(b), each particle element has two nodes in contact surface, and each node is located between two nodes of the substrate element. In the flowchart, the subscripts $p_{1}$ and $p_{2}$ refer to the parameters associated with nodes $p_{1}$ and $p_{2}$. In addition, the subscripts $s_{1}-s_{2}$ and $s_{2}-s_{3}$ refer to the averaged parameters for nodes $s_{1}, s_{2}$ and $s_{2}, s_{3}$, respectively. The flowchart is divided into two columns. In each column, parameters of each particle node, i.e., $p_{1}$ (on the left column for the example illustrated) or $p_{2}$ (on the

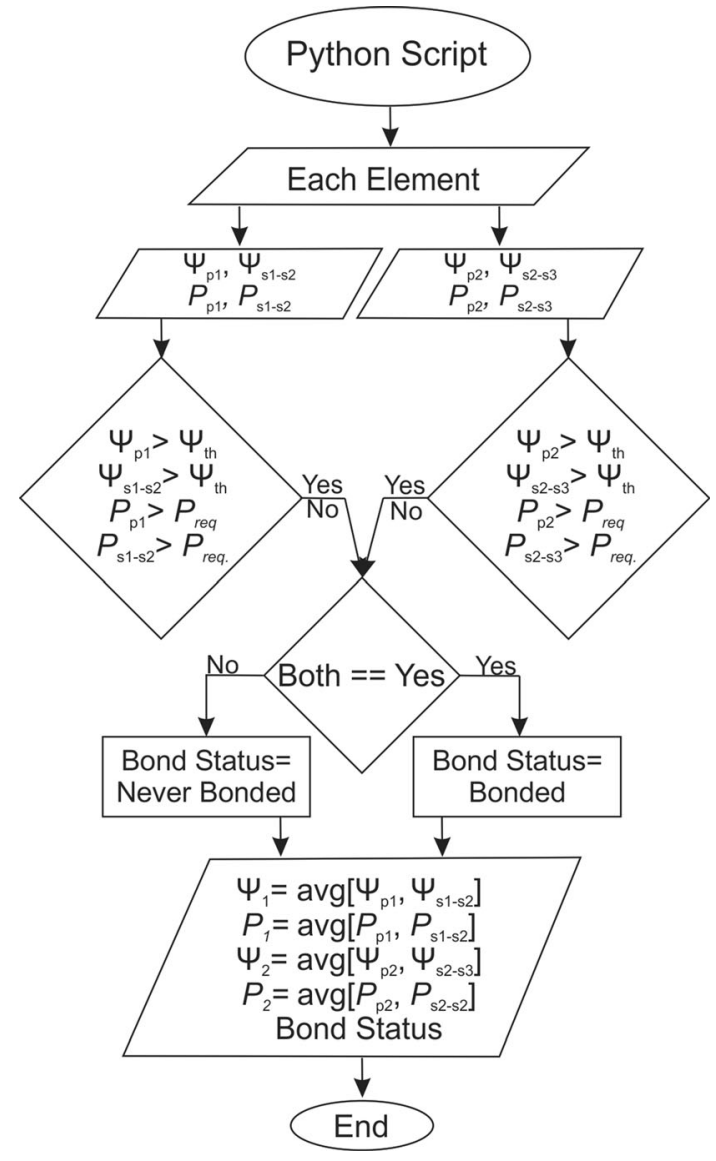

Fig. 9 Algorithm flowchart of the (Python) script

right column for the example illustrated), and the related substrate nodes, i.e., $s_{1}-s_{2}$ or $s_{2}-s_{3}$, are checked.

For each column, a verification is made to determine if $\Psi$ and $P$ meet the minimum requirements for bonding (i.e., surface expansion threshold, $\Psi_{\text {th }}$, obtained from Fig. 6 and required pressure, $P_{\text {req }}$, obtained from Fig. 7). If the minimum requirements are fulfilled, the bond status of the 
element is changed to "Bonded," otherwise the bond status remains "Never Bonded." Hence, this step allows determining which elements have achieved bonding to the substrate during the first phase of the impact process (prior to the rebounding/elastic energy release phase) and which one did not. At the end, the bond status of each element, the average surface expansion, and the average pressure between each node of the particle and the substrate nodes are saved in each frame, and the maximum is written in a data file to be sent to the next step.

\section{Restarting the Rest of the Simulation}

Afterward, the restart simulation is launched for the second part using the restart files from the first part and the data from the post-processing part.

Checking bonding quality, or comparison of the local bond strength and "negative" pressure (or tension), $P_{N}$, applied on each element during the rebounding process is made through a VUINTER user subroutine. The VUINTER subroutine is used to define the interaction between contact surfaces in ABAQUS/Explicit (Ref 57). The contact interaction is modeled by the surface-to-surface penalty contact method.

Figure 10 illustrates schematically the penalty contact method and the definition of bonding between nodes which was implemented in VUINTER subroutine (Ref 57). In the penalty contact method, the interaction is defined via spring elements which model the contact stiffness. The surfaces can penetrate each other slightly in this approach. The interpenetration causes a contact pressure in the normal direction that tries to prevent more penetration of surfaces. The maximum penetration, $h_{\max }$, is obtained after several iterations to find the best contact stiffness and pressure. For details about penalty method and its implementation in FEM, the reader is referred to
(Ref 57, 96). The difference between "Bonded" and "Not Bonded" nodes is also shown in Fig. 10. In the penalty method, the "Not Bonded" nodes separate instantly since the contact pressure reaches zero, as shown in Fig. 10. On the contrary, "Bonded" nodes cannot separate when the contact pressure goes to zero. To make these nodes come apart, a tension (or "negative") pressure (here, debonding pressure) must be applied on these nodes and exceed the bond strength $\left(\sigma_{\mathrm{B}}\right)$. Afterward, "Bonded" nodes are allowed to be detached, and contact pressure reaches zero (Fig. 10).

The bond strength $\sigma_{\mathrm{B}}$ of each bonded node is calculated by Eq 12, using the parameters obtained by the Python script. Figure 11 shows the algorithm flowchart of the VUINTER subroutine. The restart files from the simulation of the first part and data files obtained from the post-processing part are used to simulate the second part. In this simulation, we have two kinds of elements in the contact region, i.e., "Bonded" and "never Bonded" elements. "Bonded" element means both nodes of the particle element are bonded to the substrate nodes, and "never Bonded" element means at least one of the two nodes is not bonded. As shown in Fig. 10, "never Bonded" elements detach instantly when the contact pressure is removed, or in other words, these elements are not able to resist any "negative" pressure (tension). However, "Bonded" elements are able to stand out against "negative" pressure (tension) until the pressure value is larger than their bond strength. In the latter case, the element status is changed to "Debonded." At the end of the deformation, the particle and substrate have been deformed at high strain rates and because of the high amount of work hardening, both particle and substrate behave like low ductility materials. Thus, a fracture between the particle and substrate is assumed to be similar to brittle failure.

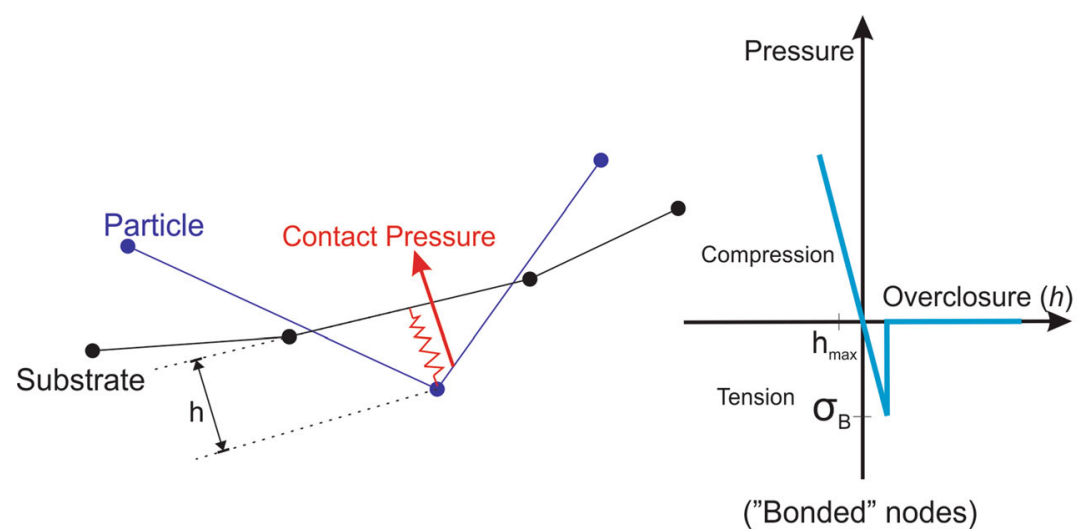

("Bonded" nodes)

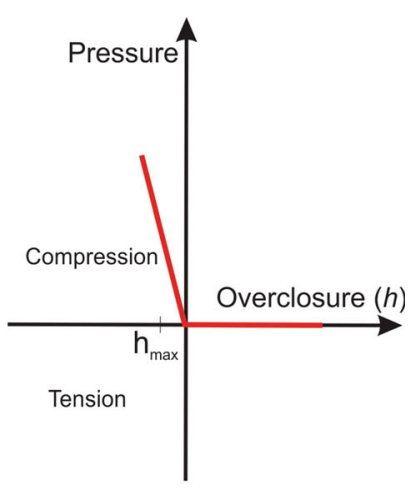

("Not Bonded" nodes)

Fig. 10 Simple schematic of penalty contact method and relationship between contact pressure and overclosure of particle-substrate nodes in VUINTER subroutine 


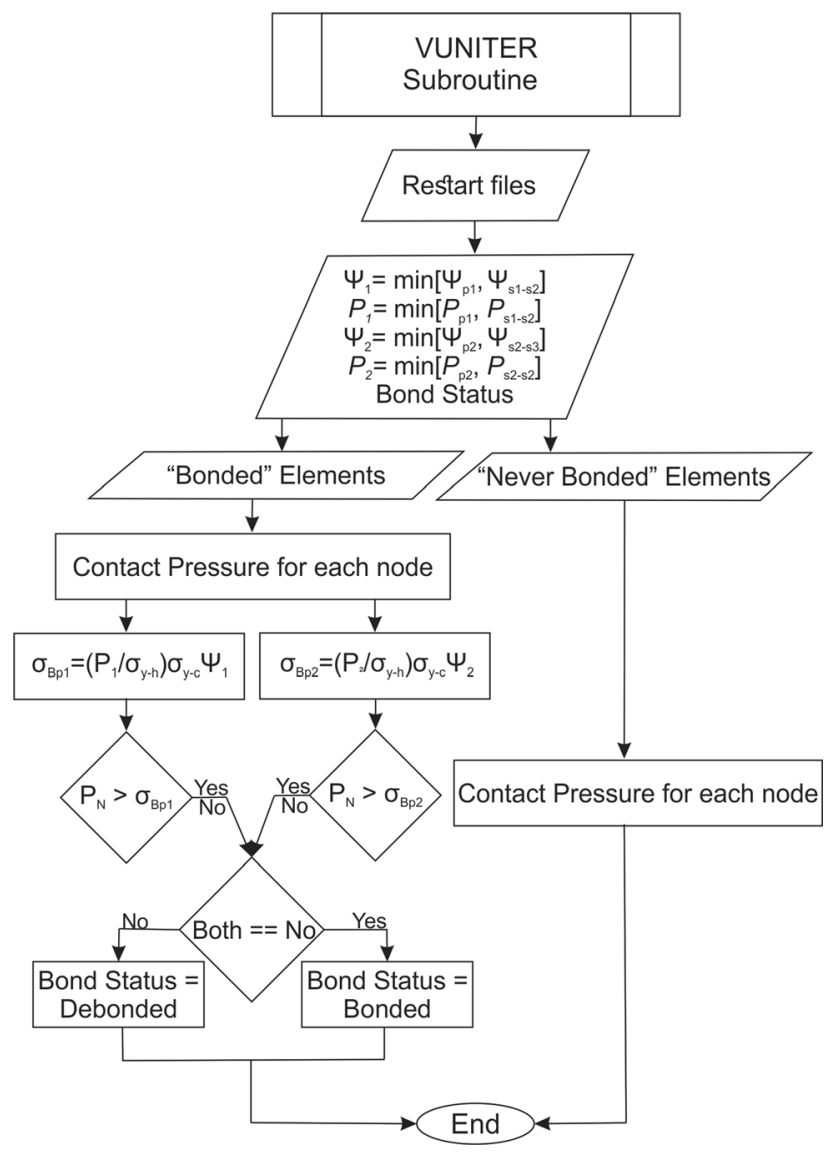

Fig. 11 Algorithm flowchart of the VUINTER subroutine

\section{Results and Discussion}

To find the critical velocity for 30-um aluminum particles, and thus assess the new impact-bonding model, several simulations were conducted with different impact velocities. The first impact velocity was set equal to $120 \mathrm{~m} / \mathrm{s}$, and then the impact velocity was increased by $50 \mathrm{~m} / \mathrm{s}$ until getting the first results of particle adhesion to the substrate. After that, the impact velocity was decreased by $10 \mathrm{~m} / \mathrm{s}$ to find the minimum velocity needed to deposit the particle. Furthermore, convergence and mesh independence of the solution were performed; a series of simulations were conducted to verify the predicted critical velocity for 30-um aluminum using different mesh sizes. The accepted mesh size in CS simulations is $1 / 50$ of particle diameter (Ref 1, 21, 34, 72). This mesh size is optimum for predicting the overall shape of deformed particle/substrate but it was found to be too coarse to show the convergence for local bonding. Figure 12 demonstrates that results converge to a solution with the size around 1/200 of particle diameter, thus substantially finer grid. Hence, the mesh size was set to $1 / 200$ of particle diameter for all other simulations in this study.

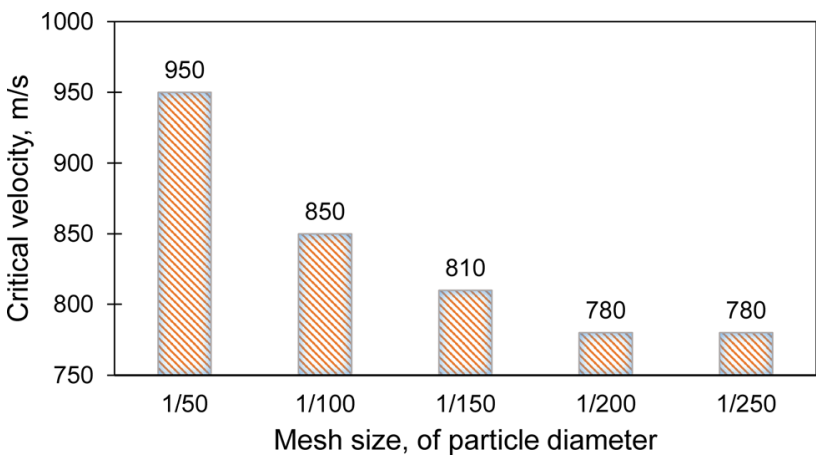

Fig. 12 Predicted critical velocity with using different mesh size for 30-um aluminum particle

As mentioned previously, when a particle hits the substrate, a large pressure wave is generated in both the particle and the substrate, and causes plastic deformation at a high strain rate. By receding from the contact center to the edges of the contact, the pressure is decreasing and shear stress is increasing. The maximum and minimum shear stresses are at the edges and center of the contact zone, respectively. Therefore, the maximum equivalent plastic strain, i.e., PEEQ, is developed at the surfaces near the edges of the contact region as shown in Fig. 13 (for 30-um aluminum particle and substrate with the impact velocity of $780 \mathrm{~m} / \mathrm{s}$ ).

The PEEQ is calculated from all plastic strain components. Nonetheless, the surface expansion, $\Psi$, is only a function of radial and hoop plastic strain of each element. Therefore, the surface expansion distribution is different from the PEEK distribution. That is to say, the most suitable zone for bonding is not necessarily the region exhibiting the highest PEEQ. Furthermore, a minimum pressure is required to extrude the material and create bonding. In addition, the same conditions should be satisfied for the elements of the substrate. Figure 14 shows the comparison between the distributions of PEEQ, surface expansion $\Psi$, and the status of bonding in the contact zone for a 30-um aluminum particle with $780 \mathrm{~m} / \mathrm{s}$ impact velocity.

As can be observed, the zone which has the maximum $\Psi$ is different from the zone of maximum PEEQ. Moreover, the bonded area is away from the jetting zone, and it is closer to the south pole of the particle. This is because enough pressure is required to extrude the fresh material through the gaps and create the intimate contact between them. The elements in the jetting zone did not create bonding because the stress is almost pure shear, and there is not a large enough normal stress to press materials together.

Experimental studies investigating bonding in CS also have presented similar results for the bonding location between particles and substrates. For instance, King et al. 

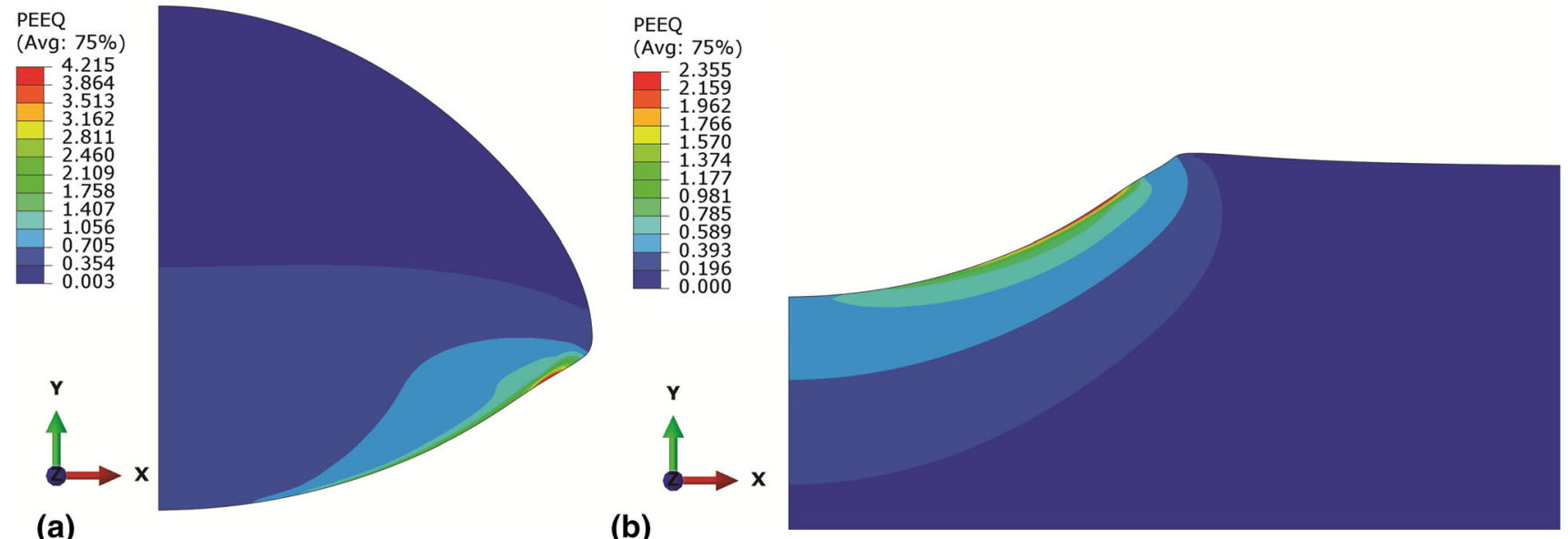

Fig. 13 Equivalent plastic strain for 30-um aluminum particle after the impact by $780 \mathrm{~m} / \mathrm{s}$ to an aluminum substrate, (a) particle (b) substrate

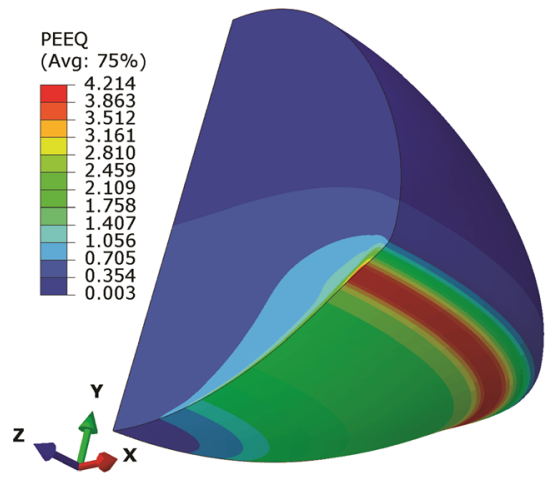

(a)

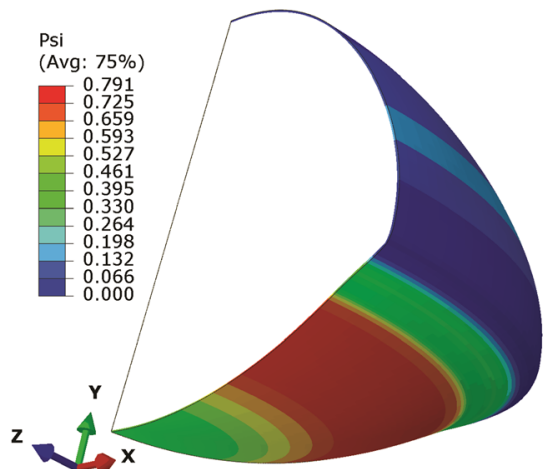

(b)

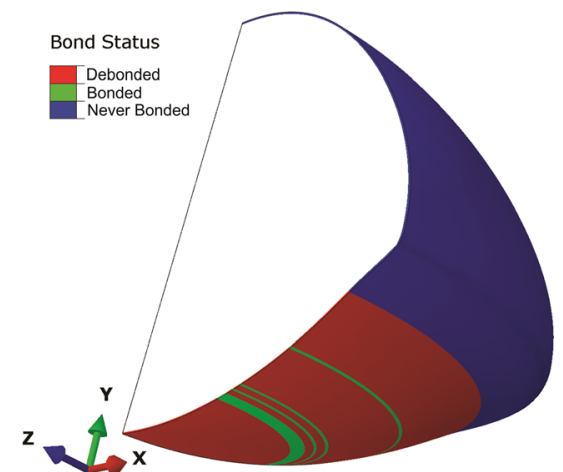

(c)

Fig. 14 (a) Equivalent plastic strain (b) surface expansion $\Psi$ (c) status of bonding in elements, for 30-um aluminum particle with $780 \mathrm{~m} / \mathrm{s}$ impact velocity

Fig. 15 (a) SEM image of bonded zone in CS, dimple fracture indicates the area of metallic bonding on copper particle, this figure was taken after detaching the deposited particle from substrate (Ref 61), (b) bottom view of Fig. 14c, bonded area is shown by arrow

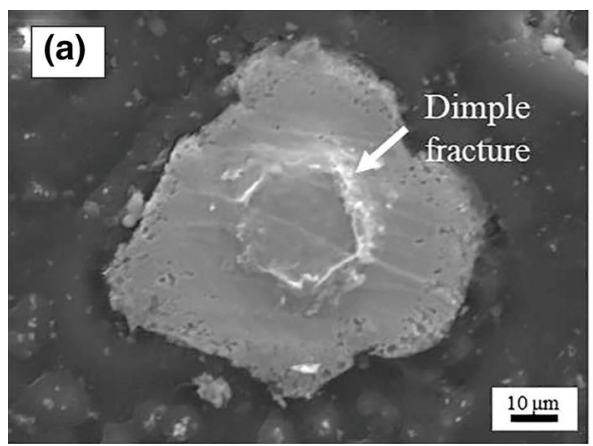

(b)

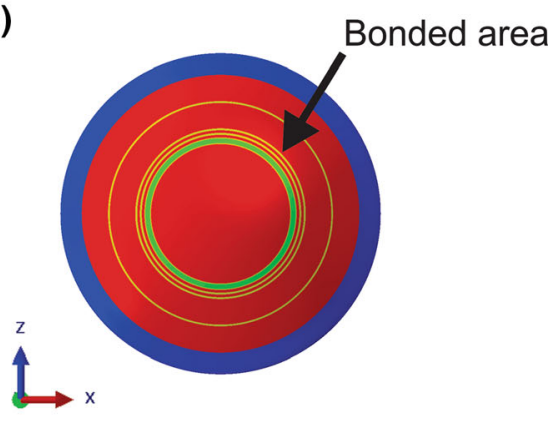

(Ref 97), Kim et al. (Ref 98), and Vidaller et al. (Ref 99) showed similar results for $\mathrm{Cu}, \mathrm{Ti}$, and Ti6Al4V, respectively. Based on the published literature, there is no such study on aluminum. Therefore, qualitative comparison was made between the predicted results and the experimental results from copper (Ref 61). Figure 15 shows an SEM image of the bottom of a deposited copper particle (Ref
61). This image was taken after detaching the particle from the substrate. Dimple fracture which is shown by arrow indicates the area of the metallic bonding on the particle. As shown in Fig. 15(b), a similar qualitative behavior is predicted by the model, giving some confidence about the modeling approach. 
Hassani-Gangaraj et al. (Ref 43) obtained the critical velocity of copper, aluminum, nickel, and zinc particles precisely and presented the coefficient of restitution (defined as the ratio between the rebound velocity and the impact velocity) as a function of impact velocity for those materials. Their experimental measurements have revealed a shift of the critical velocity from $825 \mathrm{~m} / \mathrm{s}$ for $16 \mathrm{um} \mathrm{Al}$ particles to $770 \mathrm{~m} / \mathrm{s}$ for 30-um Al particles (Ref 43), indicating that the smaller particles require lower velocities to deposit. The obtained results by the proposed model are in agreement with those results. The critical velocities were calculated to be $830 \mathrm{~m} / \mathrm{s}$ and $780 \mathrm{~m} / \mathrm{s}$ for 16 and 30-um Al particles, respectively.

Figure 16(a) shows the comparison between the predicted coefficient of restitution (COR) for 30-um aluminum particles and experimental results of aluminum powders with the diameters in range of 20-64 um obtained by Hassani-Gangaraj et al. (Ref 43). To calculate the COR for
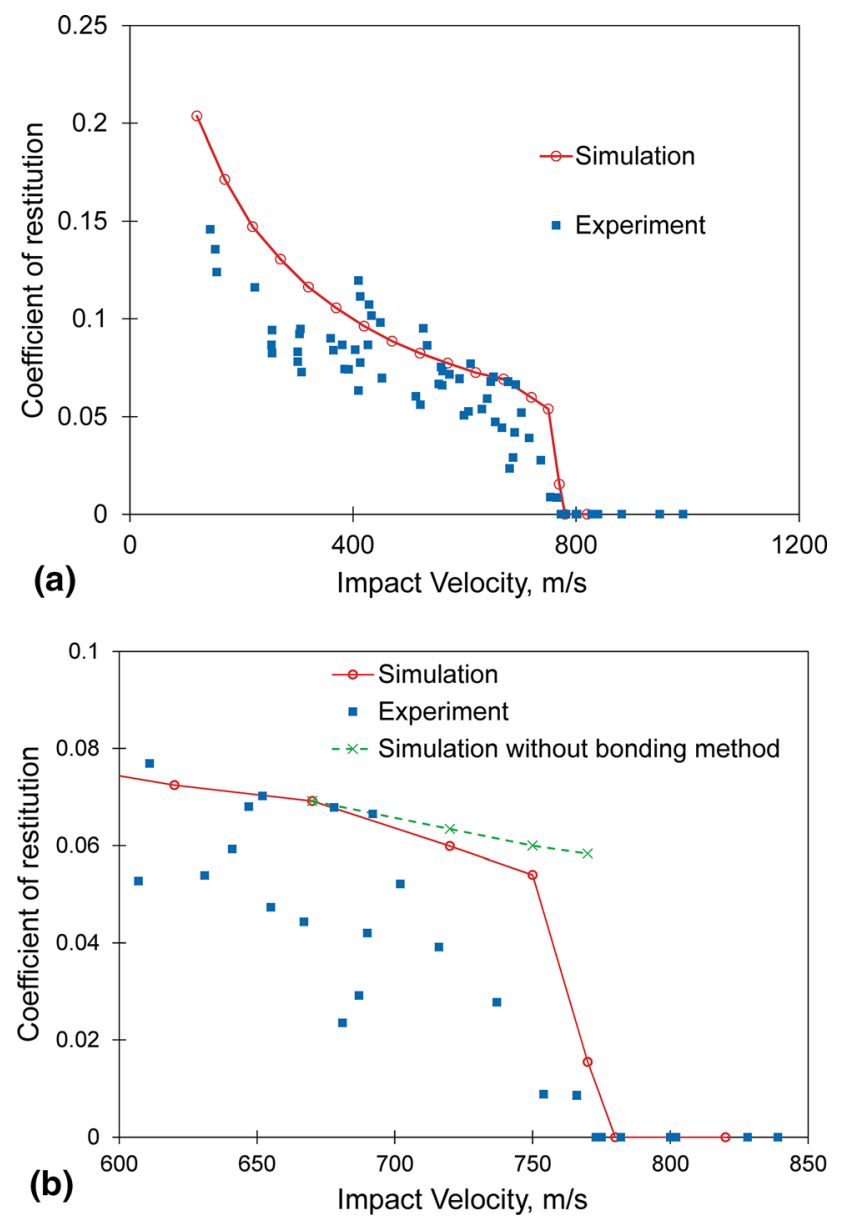

Fig. 16 (a) Coefficient of restitution as a function of impact velocity for aluminum, (b) redrawn of fig. a with changing in scales to have a better view for COR at velocities near the critical velocity of 30-um aluminum particle and simulation results without using bonding method (ABAQUS default), experiment after Hassani-Gangaraj et al. (Ref 43) numerical results, the kinetic energy equation was used to calculate the rebound velocity, $v_{\mathrm{r}}$, of the particle for each simulation as follows:

$v_{\mathrm{r}}=\sqrt{2 \frac{E_{\mathrm{K}}}{m_{\mathrm{p}}}}$

where $E_{\mathrm{K}}$ is the kinetic energy of the particle after complete detaching from the substrate, and $m_{\mathrm{p}}$ is the mass of the particle.

The COR is declining with the increase in the particle impact velocity in both numerical and experimental results, and it drops to zero at $780 \mathrm{~m} / \mathrm{s}$ and $770 \mathrm{~m} / \mathrm{s}$, respectively. The critical velocity is the minimum velocity for deposition of particles, and it means that the overall bond strength between the particle, and the substrate was higher than the pressure on the bonded zone during the elastic energy restitution part of the impact. The creation of bonds between particle and substrate starts in velocities below the critical velocity. However, the particle detaches from the substrate because its overall bond strength is less than the pressure pulling on the bonded areas when elastic energy is restored. By looking at Fig. 16(a), it can be seen that the slope of the numerical results changes beyond the impact velocity of $720 \mathrm{~m} / \mathrm{s}$. This velocity, i.e., $720 \mathrm{~m} / \mathrm{s}$, is the minimum velocity at which some elements created bonding upon impact. For the sake of clarity, the scale of Fig. 16(a) is changed, and the results are redrawn in Fig. 16(b). Furthermore, four other simulations were performed with the impact velocities of $670,720,750$, and $770 \mathrm{~m} / \mathrm{s}$ without using the new bonding method. The computed COR are plotted in Fig. 16(b). At $670 \mathrm{~m} / \mathrm{s}$, no element was bonded during the simulation. Therefore, the COR of both methods (with and without bonding method) are exactly the same. By increasing the impact velocity, it can be seen that the difference between the computed CORs is increasing. This increase in the differences indicates that more and more elements bond by increasing the impact velocity.

The kinetic energy history of a 30-um aluminum particle with the impact velocity of $750 \mathrm{~m} / \mathrm{s}$ is shown in Fig. 17. As shown in this figure, the kinetic energy of the particle goes to zero (compared to the initial kinetic energy that was $0.01 \mathrm{~mJ}$ ) around $30 \mathrm{~ns}$, i.e., end of the "impact" process. It means the particle is almost stopped at this moment. Afterward, the particle starts to bounce off due to the releasing of the elastic energy. It can be seen that the kinetic energy is increasing and reaches a maximum at around $35 \mathrm{~ns}$. This $5 \mathrm{~ns}$ period between 30 and $35 \mathrm{~ns}$ is the accelerating time during which the substrate and particle move together while they release their elastic energies. The time at the peak in this graph ( $35 \mathrm{~ns})$ indicates the time at which the substrate was stopped because of its boundary 


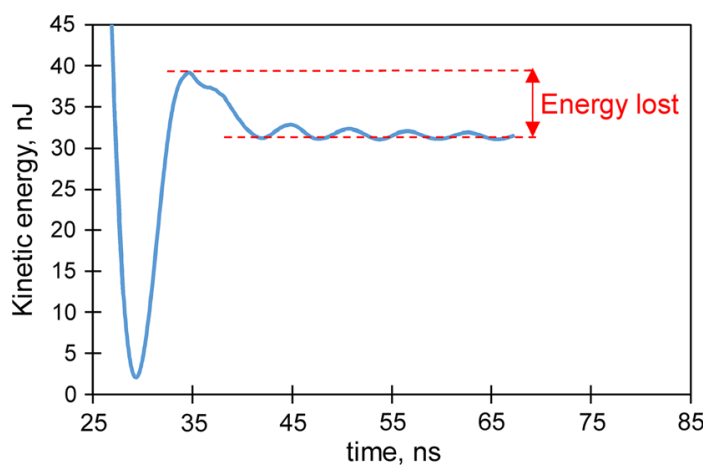

Fig. 17 History of kinetic energy of a 30-um aluminum particle with the impact velocity of $750 \mathrm{~m} / \mathrm{s}$ during the rebounding process

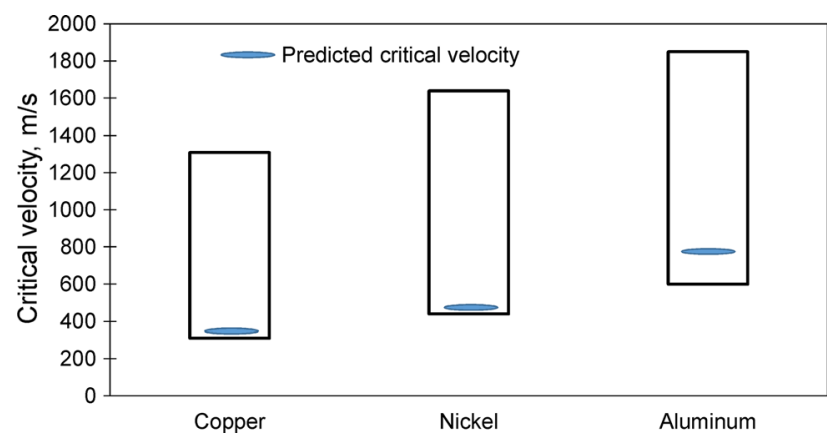

Fig. 18 Comparison of predicted critical velocity with experimental ranges of critical velocity for copper, nickel, and aluminum (Ref $1,19,38,100)$

conditions. At this velocity, the particle is bonded to the substrate by several elements. The decrease in the kinetic energy is due to the lost energy to break the bond between those elements. The overall required energy to debond all elements is shown in this figure as "energy lost."

The same procedures were applied for 12 um copper particles and 12 um nickel particles to determine the critical velocity. Comparison of the calculated critical velocity with experimental data $(\operatorname{Ref} 1,19,38,100)$ for each material is shown in Fig. 18. The obtained critical velocities were $370 \mathrm{~m} / \mathrm{s}$ for $12 \mathrm{um}$ copper, $780 \mathrm{~m} / \mathrm{s}$ for 30 -um aluminum, and $460 \mathrm{~m} / \mathrm{s}$ for 12 um nickel. As it can be seen, the predicted results are in the range of critical velocities reported in the literature (Ref 1, 19, 38, 100). This large range of reported critical velocities is due to the differences in spray system setups (such as low-pressure or highpressure CS system, nozzle material, and carrier gas type), different particle sizes and different particle oxygen content, with the latter having a dramatic effect on the particle critical velocity (Ref 38,41$)$. The reported critical velocity by Hassani-Gangaraj et al. (Ref 43) of 16, and 30-um aluminum particles are matched by the predicted critical velocities using the proposed method. Nevertheless, the obtained critical velocities for copper and nickel do not match as well the results reported by Hassani-Gangaraj et al. (Ref 43). This difference is attributed to potential dissimilarity between modeled and experimental material properties. In other words, oxidation and impurity can change the mechanical properties of materials, and these were not included in the model material properties due to lack of available data.

Future research should be devoted to develop the understanding of the material behavior in the CS process. For instance, oxide layer thickness has a strong effect on the critical velocity of the particle and the occurrence of the bonding between materials. In addition, the second particle collision effects on the metallurgical bonding between the first particle and the substrate, and also studying the bonding behavior between particles are also interesting and important subjects for future work to explore.

\section{Conclusion}

In the present study, a novel FEM modeling method is proposed to predict and study metallic bonding formation mechanisms in CS. The bonding model is based on cold welding bonding theory and experimental data.

The modeling deposition process is divided into two parts. In the first part, the particle impact on the substrate is modeled, involving plastic deformation at high strain rates for both particle and substrate material. In the second part, characterized by the releasing of the particle and mostly substrate elastic energy, the particle rebounding status from substrate is modeled, comparing the local adhesion strength to the local debonding pressure.

The bonding zone at the particle/substrate interface was modeled and investigated locally and revealed that the preferential bonding zone differs from the jetting zone where the maximum plastic deformation occurs. Moreover, the comparison between the predicted bonding zone and experimental observation showed a good agreement. Furthermore, the coefficient of restitution 30-um aluminum particles was predicted and compared well with experimental data. The critical velocity for $\mathrm{Al}, \mathrm{Cu}$, and $\mathrm{Ni}$ were obtained using the proposed method and are in the range of experimental results reported in the literature.

Acknowledgments The authors would like to express our thanks to Dr. M. Hassani-Gangaraj (Cornell University) for sharing his invaluable experimental results.

\section{References}

1. H. Assadi, F. Gärtner, T. Stoltenhoff, and H. Kreye, Bonding Mechanism in Cold Gas Spraying, Acta Mater., 2003, 51(15), p 4379-4394. https://doi.org/10.1016/S1359-6454(03)00274-X 
2. H. Assadi, H. Kreye, F. Gärtner, and T. Klassen, Cold Spraying-A Materials Perspective, Acta Mater., 2016, 116, p 382407. https://doi.org/10.1016/J.ACTAMAT.2016.06.034

3. J.G. Legoux, E. Irissou, and C. Moreau, Effect of Substrate Temperature on the Formation Mechanism of Cold-Sprayed Aluminum, Zinc and Tin Coatings, J. Therm. Spray Technol., 2007, 16(5), p 619-626. https://doi.org/10.1007/s11666-0079091-y

4. Y.-Y. Wang, Y. Liu, C.-J. Li, G.-J. Yang, and K. Kusumoto, Electrical and Mechanical Properties of Nano-Structured TiN Coatings Deposited by Vacuum Cold Spray, Vacuum, Pergamon, 2012, 86(7), p 953-959. https://doi.org/10.1016/J. VACUUM.2011.06.026

5. Y. Li, C.-J. Li, Q. Zhang, G.-J. Yang, and C.-X. Li, Influence of TGO Composition on the Thermal Shock Lifetime of Thermal Barrier Coatings with Cold-Sprayed MCrAlY Bond Coat, $J$. Therm. Spray Technol., 2010, 19(1), p 168-177. https://doi.org/ 10.1007/s11666-009-9372-8

6. Q. Zhang, C.-J. Li, C.-X. Li, G.-J. Yang, and S.-C. Lui, Study of Oxidation Behavior of Nanostructured NiCrAlY Bond Coatings Deposited by Cold Spraying, Surf. Coatings Technol., 2008, 202(14), p 3378-3384. https://doi.org/10.1016/J.SURFCOAT. 2007.12.028

7. P.C. King, A.J. Poole, S. Horne, R. de Nys, S. Gulizia, and M.Z. Jahedi, Embedment of Copper Particles into Polymers by Cold Spray, Surf. Coatings Technol., 2013, 216, p 60-67. https://doi. org/10.1016/J.SURFCOAT.2012.11.023

8. R. Lupoi and W. O'Neill, Deposition of Metallic Coatings on Polymer Surfaces Using Cold Spray, Surf. Coatings Technol., 2010, 205(7), p 2167-2173. https://doi.org/10.1016/J.SURF COAT.2010.08.128

9. K.-R. Donner, F. Gaertner, and T. Klassen, Metallization of Thin $\mathrm{Al}_{2} \mathrm{O}_{3}$ Layers in Power Electronics Using Cold Gas Spraying, J. Therm. Spray Technol., 2011, 20(1), p 299-306. https://doi.org/10.1007/s11666-010-9573-1

10. J. King, C. Peter, S.H. Zahiri, M. Jahedi, and J. Friend, Cold Spray Electroding of Piezoelectric Ceramic, Mater. Forum, 2007, 31, p 116-119

11. R.C. Dykhuizen and M.F. Smith, Gas Dynamic Principles of Cold Spray, J. Therm. Spray Technol., 1998, 7(2), p 205-212. https://doi.org/10.1361/105996398770350945

12. Z. Arabgol, M. Villa Vidaller, H. Assadi, F. Gärtner, and T. Klassen, Influence of Thermal Properties and Temperature of Substrate on the Quality of Cold-Sprayed Deposits, Acta Mater., 2017, 127, p 287-301. https://doi.org/10.1016/J.ACTAMAT. 2017.01.040

13. Y. Ichikawa, R. Tokoro, M. Tanno, and K. Ogawa, Elucidation of Cold-Spray Deposition Mechanism by Auger Electron Spectroscopic Evaluation of Bonding Interface Oxide Film, Acta Mater., 2019, 164, p 39-49. https://doi.org/10.1016/J.ACTA MAT.2018.09.041

14. W.-Y. Li and C.-J. Li, Characterization of Cold-Sprayed Nanostructured Fe-Based Alloy, Appl. Surf. Sci., 2010, 256(7), p 2193-2198. https://doi.org/10.1016/J.APSUSC.2009.09.072

15. R. Ghelichi, D. MacDonald, S. Bagherifard, H. Jahed, M. Guagliano, and B. Jodoin, Microstructure and Fatigue Behavior of Cold Spray Coated A15052, Acta Mater., 2012, 60(19), p 6555-6561. https://doi.org/10.1016/J.ACTAMAT.2012.08.020

16. G.-J. Yang, C.-J. Li, F. Han, W.-Y. Li, and A. Ohmori, Low Temperature Deposition and Characterization of $\mathrm{TiO}_{2}$ Photocatalytic Film through Cold Spray, Appl. Surf. Sci., 2008, 254(13), p 3979-3982. https://doi.org/10.1016/J.APSUSC.2007. 12.016

17. T. Suhonen, T. Varis, S. Dosta, M. Torrell, and J.M. Guilemany, Residual Stress Development in Cold Sprayed $\mathrm{Al}, \mathrm{Cu}$ and $\mathrm{Ti}$
Coatings, Acta Mater., 2013, 61(17), p 6329-6337. https://doi. org/10.1016/J.ACTAMAT.2013.06.033

18. M. Grujicic, C.L. Zhao, W.S. DeRosset, and D. Helfritch, Adiabatic Shear Instability Based Mechanism for Particles/ Substrate Bonding in the Cold-Gas Dynamic-Spray Process, Mater. Des., 2004, 25(8), p 681-688. https://doi.org/10.1016/j. matdes.2004.03.008

19. T. Schmidt, F. Gärtner, H. Assadi, and H. Kreye, Development of a Generalized Parameter Window for Cold Spray Deposition, Acta Mater., 2006, 54(3), p 729-742

20. Y. Zou, W. Qin, E. Irissou, J.-G. Legoux, S. Yue, and J.A. Szpunar, Dynamic Recrystallization in the Particle/Particle Interfacial Region of Cold-Sprayed Nickel Coating: Electron Backscatter Diffraction Characterization, Scr. Mater., 2009, 61(9), p 899-902. https://doi.org/10.1016/J.SCRIPTAMAT. 2009.07.020

21. S. Rahmati and A. Ghaei, The Use of Particle/Substrate Material Models in Simulation of Cold-Gas Dynamic-Spray Process, $J$. Therm. Spray Technol., 2014, 23(3), p 530-540

22. G. Bae, S. Kumar, S. Yoon, K. Kang, H. Na, H.-J. Kim, and C. Lee, Bonding Features and Associated Mechanisms in Kinetic Sprayed Titanium Coatings, Acta Mater., 2009, 57(19), p 56545666. https://doi.org/10.1016/J.ACTAMAT.2009.07.061

23. G. Bae, Y. Xiong, S. Kumar, K. Kang, and C. Lee, General Aspects of Interface Bonding in Kinetic Sprayed Coatings, Acta Mater., 2008, 56(17), p 4858-4868. https://doi.org/10.1016/J. ACTAMAT.2008.06.003

24. S. Barradas, V. Guipont, R. Molins, M. Jeandin, M. Arrigoni, M. Boustie, C. Bolis, L. Berthe, and M. Ducos, Laser Shock Flier Impact Simulation of Particle-Substrate Interactions in Cold Spray, J. Therm. Spray Technol., 2007, 16(4), p 548-556

25. M. Grujicic, J.R. Saylor, D.E. Beasley, W.S. DeRosset, and D. Helfritch, Computational Analysis of the Interfacial Bonding between Feed-Powder Particles and the Substrate in the ColdGas Dynamic-Spray Process, Appl. Surf. Sci., 2003, 219(3-4), p 211-227. https://doi.org/10.1016/S0169-4332(03)00643-3

26. P.C. King, G. Bae, S.H. Zahiri, M. Jahedi, and C. Lee, An Experimental and Finite Element Study of Cold Spray Copper Impact onto Two Aluminum Substrates, J. Therm. Spray Technol., 2010, 19(3), p 620-634

27. T. Schmidt, H. Assadi, F. Gärtner, H. Richter, T. Stoltenhoff, H. Kreye, and T. Klassen, From Particle Acceleration to Impact and Bonding in Cold Spraying, J. Therm. Spray Technol., 2009, 18(5-6), p 794

28. W.Y. Li, D.D. Zhang, C.J. Huang, S. Yin, M. Yu, F.F. Wang, and H.L. Liao, Modelling of Impact Behaviour of Cold Spray Particles: Review, Surf. Eng., 2014, 30(5), p 299-308. https:// doi.org/10.1179/1743294414Y.0000000268

29. G. Archambault, B. Jodoin, S. Gaydos, and M. Yandouzi, Metallization of Carbon Fiber Reinforced Polymer Composite by Cold Spray and Lay-up Molding Processes, Surf. Coatings Technol., 2016, 300, p 78-86. https://doi.org/10.1016/J.SURF COAT.2016.05.008

30. T. Samson, D. MacDonald, R. Fernández, and B. Jodoin, Effect of Pulsed Waterjet Surface Preparation on the Adhesion Strength of Cold Gas Dynamic Sprayed Aluminum Coatings, $J$. Therm. Spray Technol., 2015, 24(6), p 984-993. https://doi.org/ 10.1007/s11666-015-0261-z

31. F. Khodabakhshi, B. Marzbanrad, H. Jahed, and A.P. Gerlich, Interfacial Bonding Mechanisms between Aluminum and Titanium during Cold Gas Spraying Followed by Friction-Stir Modification, Appl. Surf. Sci., 2018, 462, p 739-752. https://doi. org/10.1016/j.apsusc.2018.08.156

32. M. Walker, Microstructure and Bonding Mechanisms in Cold Spray Coatings, Mater. Sci. Technol., 2018, 34(17), p 20572077. https://doi.org/10.1080/02670836.2018.1475444 
33. W.-Y. Li and W. Gao, Some Aspects on 3D Numerical Modeling of High Velocity Impact of Particles in Cold Spraying by Explicit Finite Element Analysis, Appl. Surf. Sci., 2009, 255(18), p 7878-7892. https://doi.org/10.1016/J.APSUSC.2009. 04.135

34. L. Zhu, T.-C. Jen, Y.-T. Pan, and H.-S. Chen, Particle Bonding Mechanism in Cold Gas Dynamic Spray: A Three-Dimensional Approach, J. Therm. Spray Technol., 2017, 26(8), p 1859-1873. https://doi.org/10.1007/s11666-017-0652-4

35. Y. Xie, S. Yin, C. Chen, M.-P. Planche, H. Liao, and R. Lupoi, New Insights into the Coating/Substrate Interfacial Bonding Mechanism in Cold Spray, Scr. Mater., 2016, 125, p 1-4. https:// doi.org/10.1016/J.SCRIPTAMAT.2016.07.024

36. T. Stoltenhoff, H. Kreye, and H.J. Richter, An Analysis of the Cold Spray Process and Its Coatings, J. Therm. Spray Technol., 2002, 11(4), p 542-550

37. H.-J. Kim, C.-H. Lee, and S.-Y. Hwang, Fabrication of WC-Co Coatings by Cold Spray Deposition, Surf. Coatings Technol., 2005, 191(2), p 335-340. https://doi.org/10.1016/j.surfcoat.2004. 04.058

38. M. Hassani-Gangaraj, D. Veysset, K.A. Nelson, and C.A. Schuh, Impact-Bonding with Aluminum, Silver, and Gold Microparticles: Toward Understanding the Role of Native Oxide Layer, Appl. Surf. Sci., 2019, 476, p 528-532. https://doi.org/10.1016/j. apsusc.2019.01.111

39. A. Manap, T. Okabe, K. Ogawa, S. Mahalingam, and H. Abdullah, Experimental and Smoothed Particle Hydrodynamics Analysis of Interfacial Bonding between Aluminum Powder Particles and Aluminum Substrate by Cold Spray Technique, Int. J. Adv. Manuf. Technol., 2019, 103(9), p 4519-4527. https:// doi.org/10.1007/s00170-019-03846-4

40. A. Viscusi, A. Astarita, R. Della Gatta, and F. Rubino, A Perspective Review on the Bonding Mechanisms in Cold Gas Dynamic Spray, Surf. Eng., 2019, 35(9), p 743-771. https://doi. org/10.1080/02670844.2018.1551768

41. C.-J. Li, H.-T. Wang, Q. Zhang, G.-J. Yang, W.-Y. Li, and H.L. Liao, Influence of Spray Materials and Their Surface Oxidation on the Critical Velocity in Cold Spraying, J. Therm. Spray Technol., 2010, 19(1), p 95-101. https://doi.org/10.1007/s11666009-9427-x

42. C.-J. Li and W.-Y. Li, Deposition Characteristics of Titanium Coating in Cold Spraying, Surf. Coatings Technol., 2003, 167(2), p 278-283. https://doi.org/10.1016/S02578972(02)00919-2

43. M. Hassani-Gangaraj, D. Veysset, K.A. Nelson, and C.A. Schuh, In-Situ Observations of Single Micro-Particle Impact Bonding, Scr. Mater., 2018, 145, p 9-13. https://doi.org/10.1016/J. SCRIPTAMAT.2017.09.042

44. J.-H. Lee, D. Veysset, J.P. Singer, M. Retsch, G. Saini, T. Pezeril, K.A. Nelson, and E.L. Thomas, High Strain Rate Deformation of Layered Nanocomposites, Nat. Commun, 2012, 3, p 1164. https://doi.org/10.1038/ncomms2166

45. D. Veysset, A.J. Hsieh, S. Kooi, A.A. Maznev, K.A. Masser, and K.A. Nelson, Dynamics of Supersonic Microparticle Impact on Elastomers Revealed by Real-Time Multi-Frame Imaging, Sci. Rep., 2016, 6, p 25577. https://doi.org/10.1038/srep25577

46. R.C. Dykhuizen, M.F. Smith, D.L. Gilmore, R.A. Neiser, X. Jiang, and S. Sampath, Impact of High Velocity Cold Spray Particles, J. Therm. Spray Technol., 1999, 8(4), p 559-564

47. S. Guetta, M.H. Berger, F. Borit, V. Guipont, M. Jeandin, M. Boustie, Y. Ichikawa, K. Sakaguchi, and K. Ogawa, Influence of Particle Velocity on Adhesion of Cold-Sprayed Splats, J. Therm. Spray Technol., 2009, 18(3), p 331-342

48. T. Hussain, D.G. McCartney, P.H. Shipway, and D. Zhang, Bonding Mechanisms in Cold Spraying: The Contributions of
Metallurgical and Mechanical Components, J. Therm. Spray Technol., 2009, 18(3), p 364-379

49. S. Yin, X. Suo, Y. Xie, W. Li, R. Lupoi, and H. Liao, Effect of Substrate Temperature on Interfacial Bonding for Cold Spray of $\mathrm{Ni}$ onto Cu, J. Mater. Sci., 2015, 50(22), p 7448-7457. https:// doi.org/10.1007/s 10853-015-9304-6

50. S. Yin, X. Wang, W.Y. Li, and H. Jie, Effect of Substrate Hardness on the Deformation Behavior of Subsequently Incident Particles in Cold Spraying, Appl. Surf. Sci., 2011, 257(17), p 7560-7565. https://doi.org/10.1016/j.apsusc.2011.03.126

51. W.-Y. Li, H. Liao, C.-J. Li, H.-S. Bang, and C. Coddet, Numerical Simulation of Deformation Behavior of Al Particles Impacting on Al Substrate and Effect of Surface Oxide Films on Interfacial Bonding in Cold Spraying, Appl. Surf. Sci., 2007, 253(11), p 5084-5091. https://doi.org/10.1016/J.APSUSC.2006. 11.020

52. W.-Y. Li, S. Yin, and X.-F. Wang, Numerical Investigations of the Effect of Oblique Impact on Particle Deformation in Cold Spraying by the SPH Method, Appl. Surf. Sci., 2010, 256(12), p 3725-3734. https://doi.org/10.1016/j.apsusc.2010.01.014

53. F. Meng, S. Yue, and J. Song, Quantitative Prediction of Critical Velocity and Deposition Efficiency in Cold-Spray: A FiniteElement Study, Scr. Mater., 2015, 107, p 83-87. https://doi.org/ 10.1016/j.scriptamat.2015.05.026

54. B. Yildirim, S. Muftu, and A. Gouldstone, Modeling of High Velocity Impact of Spherical Particles, Wear, 2011, 270(9-10), p 703-713

55. P. Profizi, A. Combescure, and K. Ogawa, SPH Modeling of Adhesion in Fast Dynamics: Application to the Cold Spray Process, Comptes Rendus Mécanique, 2016, 344(4), p 211-224. https://doi.org/10.1016/j.crme.2016.02.001

56. A. Manap, O. Nooririnah, H. Misran, T. Okabe, and K. Ogawa, Experimental and SPH Study of Cold Spray Impact between Similar and Dissimilar Metals, Surf. Eng., 2014, 30(5), p 335341. https://doi.org/10.1179/1743294413Y.0000000237

57. Dassault Systemes, D. S. Abaqus analysis user's guide. Technical Report Abaqus 6.14 Documentation, Simulia Corp, 2016.

58. Y.V. Kurochkin, Y.N. Demin, and S.I. Soldatenkov, Demonstration of the Method of Cold Gasdynamic Spraying of Coatings, Chem. Pet. Eng., 2002, 38(3), p 245-248. https://doi.org/ 10.1023/A:1019637513791

59. J. Wu, H. Fang, S. Yoon, H. Kim, and C. Lee, The Rebound Phenomenon in Kinetic Spraying Deposition, Scr. Mater., 2006, 54(4), p 665-669. https://doi.org/10.1016/j.scriptamat.2005.10. 028

60. W. Xie, A. Alizadeh-Dehkharghani, Q. Chen, V.K. Champagne, X. Wang, A.T. Nardi, S. Kooi, S. Müftü, and J.-H. Lee, Dynamics and Extreme Plasticity of Metallic Microparticles in Supersonic Collisions, Sci. Rep., 2017, 7(1), p 5073. https://doi. org/10.1038/s41598-017-05104-7

61. C. Chen, Y. Xie, R. Huang, S. Deng, Z. Ren, and H. Liao, On the Role of Oxide Film's Cleaning Effect into the Metallurgical Bonding during Cold Spray, Mater. Lett., 2018, 210, p 199-202. https://doi.org/10.1016/j.matlet.2017.09.024

62. W.Y. Li, C. Zhang, C.-J. Li, and H. Liao, Modeling Aspects of High Velocity Impact of Particles in Cold Spraying by Explicit Finite Element Analysis, ASM Int., 2009, 18, p 921-933

63. J. Vlcek, L. Gimeno, H. Huber, and E. Lugscheider, A Systematic Approach to Material Eligibility for the Cold-Spray Process, J. Therm. Spray Technol., 2005, 14(1), p 125-133. https://doi.org/10.1361/10599630522738

64. E.A. Flores-Johnson, M. Saleh, and L. Edwards, Ballistic Performance of Multi-Layered Metallic Plates Impacted by a 7.62Mm APM2 Projectile, Int. J. Impact Eng, 2011, 38(12), p 10221032. https://doi.org/10.1016/j.ijimpeng.2011.08.005 
65. A. Manap, T. Okabe, and K. Ogawa, Computer Simulation of Cold Sprayed Deposition Using Smoothed Particle Hydrodynamics, Procedia Eng., 2011, 10, p 1145-1150. https://doi.org/ 10.1016/J.PROENG.2011.04.190

66. B. Yildirim, H. Fukanuma, T. Ando, A. Gouldstone, and S. Müftü, A Numerical Investigation into Cold Spray Bonding Processes, J. Tribol., 2014, 137(1), p 011102

67. J. Henao, G. Bolelli, A. Concustell, L. Lusvarghi, S. Dosta, I.G. Cano, and J.M. Guilemany, Deposition Behavior of ColdSprayed Metallic Glass Particles onto Different Substrates, Surf. Coatings Technol., 2018, 349, p 13-23. https://doi.org/10.1016/J. SURFCOAT.2018.05.047

68. R. Nikbakht, S.H. Seyedein, S. Kheirandish, H. Assadi, and B. Jodoin, Asymmetrical Bonding in Cold Spraying of Dissimilar Materials, Appl. Surf. Sci., 2018, 444, p 621-632. https://doi.org/ 10.1016/J.APSUSC.2018.03.103

69. K. Yang, W. Li, X. Guo, X. Yang, and Y. Xu, Characterizations and Anisotropy of Cold-Spraying Additive-Manufactured Copper Bulk, J. Mater. Sci. Technol., 2018, 34(9), p 1570-1579. https://doi.org/10.1016/J.JMST.2018.01.002

70. G. Bolelli, S. Dosta, L. Lusvarghi, T. Manfredini, J.M. Guilemany, and I.G. Cano, Building up WC-Co Coatings by Cold Spray: A Finite Element Simulation, Surf. Coatings Technol., 2019, 374, p 674-689. https://doi.org/10.1016/J.SURFCOAT. 2019.06.054

71. W. Ma, Y. Xie, C. Chen, H. Fukanuma, J. Wang, Z. Ren, and R. Huang, Microstructural and Mechanical Properties of HighPerformance Inconel 718 Alloy by Cold Spraying, J. Alloys Compd., 2019, 792, p 456-467. https://doi.org/10.1016/J.JALL COM.2019.04.045

72. A. Nastic, M. Vijay, A. Tieu, S. Rahmati, and B. Jodoin, Experimental and Numerical Study of the Influence of Substrate Surface Preparation on Adhesion Mechanisms of Aluminum Cold Spray Coatings on $300 \mathrm{M}$ Steel Substrates, J. Therm. Spray Technol., 2017, 26(7), p 1461-1483

73. J.K. Chen, F.A. Allahdadi, and T.C. Carney, High-Velocity Impact of Graphite/Epoxy Composite Laminates, Compos. Sci. Technol., 1997, 57(9), p 1369-1379. https://doi.org/10.1016/ S0266-3538(97)00067-5

74. D.L. Preston, D.L. Tonks, and D.C. Wallace, Model of Plastic Deformation for Extreme Loading Conditions, J. Appl. Phys., 2002, 93(1), p 211-220. https://doi.org/10.1063/1.1524706

75. J.-B. Kim and H. Shin, Comparison of Plasticity Models for Tantalum and a Modification of the PTW Model for Wide Ranges of Strain, Strain Rate, and Temperature, Int. J. Impact Eng, 2009, 36(5), p 746-753. https://doi.org/10.1016/j.ijimpeng. 2008.11.003

76. B. Banerjee, An Evaluation of Plastic Flow Stress Models for the Simulation of High-Temperature and High-Strain-Rate Deformation of Metals, cond-mat.mtrl-sci, 2005, p 43.

77. D.T. Casem, J.P. Ligda, B.E. Schuster, and S. Mims, High-rate mechanical response of aluminum using miniature Kolsky bar techniques, Dynamic Behavior of Materials, Volume 1, J. Kimberley, L. Lamberson, and S. Mates, Ed., Springer, Berlin, 2018, p 147-153

78. M.C. Price, A.T. Kearsley, and M.J. Burchell, Validation of the Preston-Tonks-Wallace Strength Model at Strain Rates Approaching 1011 S - 1 for Al-1100, Tantalum and Copper Using Hypervelocity Impact Crater Morphologies, Int. J. Impact Eng, 2013, 52, p 1-10. https://doi.org/10.1016/j.ijimpeng.2012. 09.001

79. S. Yin, X. Wang, W. Li, H. Liao, and H. Jie, Deformation Behavior of the Oxide Film on the Surface of Cold Sprayed Powder Particle, Appl. Surf. Sci., 2012, 259, p 294-300. https:// doi.org/10.1016/j.apsusc.2012.07.036
80. H. Conrad and L. Rice, The Cohesion of Previously Fractured Fcc Metals in Ultrahigh Vacuum, Metall. Trans., 1970, 1(11), p 3019-3029. https://doi.org/10.1007/BF03038415

81. N. Bay, Mechanisms Producing Metallic Bonds in Cold Welding, Weld. J., 1983, 62(5), p 137

82. M. Bambach, M. Pietryga, A. Mikloweit, and G. Hirt, A Finite Element Framework for the Evolution of Bond Strength in Joining-by-Forming Processes, J. Mater. Process. Technol., 2014, 214(10), p 2156-2168. https://doi.org/10.1016/j.jmatpro tec.2014.03.015

83. W. Zhang and N. Bay, Cold Welding-Theoretical Modeling of the Weld Formation, Weld. Journal-Including Weld. Res. Suppl., 1997, 76(10), p 477s

84. K.H. Ko, J.O. Choi, H. Lee, Y.K. Seo, S.P. Jung, and S.S. Yu, Cold Spray Induced Amorphization at the Interface between $\mathrm{Fe}$ Coatings and Al Substrate, Mater. Lett., 2015, 149, p 40-42. https://doi.org/10.1016/J.MATLET.2015.02.118

85. W.-Y. Li, C.-J. Li, and G.-J. Yang, Effect of Impact-Induced Melting on Interface Microstructure and Bonding of ColdSprayed Zinc Coating, Appl. Surf. Sci., 2010, 257(5), p 15161523. https://doi.org/10.1016/J.APSUSC.2010.08.089

86. T. Marrocco, D.G. McCartney, P.H. Shipway, and A.J. Sturgeon, Production of Titanium Deposits by Cold-Gas Dynamic Spray: Numerical Modeling and Experimental Characterization, J. Therm. Spray Technol., 2006, 15(2), p 263-272. https://doi. org/10.1361/105996306X108219

87. M. Ševeček, A. Gurgen, A. Seshadri, Y. Che, M. Wagih, B. Phillips, V. Champagne, and K. Shirvan, Development of $\mathrm{Cr}$ Cold Spray-Coated Fuel Cladding with Enhanced Accident Tolerance, Nucl. Eng. Technol., 2018, 50(2), p 229-236. https:// doi.org/10.1016/J.NET.2017.12.011

88. L. Shen, L. Kong, T. Xiong, H. Du, and T. Li, Preparation of $\mathrm{TiAl}_{3}-\mathrm{Al}$ Composite Coating by Cold Spraying, Trans. Nonferrous Met. Soc. China, 2009, 19(4), p 879-882. https://doi.org/ 10.1016/S1003-6326(08)60369-6

89. Y. Xiong, G. Bae, X. Xiong, and C. Lee, The Effects of Successive Impacts and Cold Welds on the Deposition Onset of Cold Spray Coatings, J. Therm. Spray Technol., 2010, 19(3), p 575-585. https://doi.org/10.1007/s11666-009-9455-6

90. Y. Xiong, X. Xiong, S. Yoon, G. Bae, and C. Lee, Dependence of Bonding Mechanisms of Cold Sprayed Coatings on StrainRate-Induced Non-Equilibrium Phase Transformation, J. Therm. Spray Technol., 2011, 20(4), p 860-865. https://doi.org/10.1007/ s11666-011-9634-0

91. N. Bay, C. Clemensen, O. Juelstorp, and T. Wanheim, Bond Strength in Cold Roll Bonding, CIRP Ann., 1985, 34(1), p 221224. https://doi.org/10.1016/S0007-8506(07)61760-0

92. R.G. McQueen and S.P. Marsh, Ultimate Yield Strength of Copper, J. Appl. Phys., 1962, 33(2), p 654-665. https://doi.org/ 10.1063/1.1702483

93. W. Johnson, Extrusion through Wedge-Shaped Dies. Part I, $J$. Mech. Phys. Solids, 1955, 3(3), p 218-223. https://doi.org/10. 1016/0022-5096(55)90014-4

94. R. Hill, The Mathematical Theory of Plasticity, Clarendon Press, Oxford, 1950

95. R.M. Jones, Deformation Theory of Plasticity, Bull Ridge Corporation, Blacksburg, 2009

96. S. Atlati, B. Haddag, M. Nouari, and M. Zenasni, Thermomechanical Modelling of the Tool-Workmaterial Interface in Machining and Its Implementation Using the ABAQUS VUINTER Subroutine, Int. J. Mech. Sci., 2014, 87, p 102-117. https://doi.org/10.1016/j.ijmecsci.2014.05.034

97. P.C. King, S.H. Zahiri, and M. Jahedi, Microstructural Refinement within a Cold-Sprayed Copper Particle, Metall. Mater. Trans. A, 2009, 40(9), p 2115-2123. https://doi.org/10.1007/ s11661-009-9882-5 
98. K. Kim, M. Watanabe, K. Mitsuishi, K. Iakoubovskii, and S. Kuroda, Impact Bonding and Rebounding between Kinetically Sprayed Titanium Particle and Steel Substrate Revealed by High-Resolution Electron Microscopy, J. Phys. D Appl. Phys., 2009, 42(6), p 65304. https://doi.org/10.1088/0022-3727/42/6/ 065304

99. M.V. Vidaller, A. List, F. Gaertner, T. Klassen, S. Dosta, and J.M. Guilemany, Single Impact Bonding of Cold Sprayed Ti6Al-4 V Powders on Different Substrates, J. Therm. Spray Technol., 2015, 24(4), p 644-658. https://doi.org/10.1007/ s11666-014-0200-4

100. A. Rezaeain, R. Chromik, S. Yue, E. Irissou, and J.G. Legoux, Characterization of Cold-Sprayed $\mathrm{Ni}, \mathrm{Ti}$ and $\mathrm{Cu}$ Coating
Properties for Their Optimizations, Therm. Spray 2008 Therm. Spray Crossing Borders, 2008, 2008, p 2-4

101. Y. Cormier, P. Dupuis, B. Jodoin, and A. Ghaei, Finite Element Analysis and Failure Mode Characterization of Pyramidal Fin Arrays Produced by Masked Cold Gas Dynamic Spray, J. Therm. Spray Technol., 2015, 24(8), p 1549-1565. https://doi. org/10.1007/s11666-015-0317-0

Publisher's Note Springer Nature remains neutral with regard to jurisdictional claims in published maps and institutional affiliations. 